\title{
Effects and Interplays of Spray Angle and Stand-off Distance on the Sliding Wear Behavior of HVOF WC-17Co Coatings
}

\author{
Vasileios Katranidis $^{1} \cdot$ Spyros Kamnis $^{2} \cdot$ Bryan Allcock $^{2} \cdot$ Sai Gu $^{1}$
}

Submitted: 7 October 2018/in revised form: 2 December 2018/Published online: 23 January 2019

(C) The Author(s) 2019

\begin{abstract}
The state of particle impact (velocity and temperature) significantly affects the coating's microstructural, mechanical properties and wear performance. The spray stand-off distance and spray angle dictate particle velocity components and temperature at impact. This work aims in advancing the understanding of their effect and interplay in regard to the sliding wear performance as well as the mechanisms of wear themselves of HVOF-sprayed WC17Co coatings. Dry sliding wear resistance was evaluated by a pin-on-disk test, and significant interplay between the spray parameters was observed. A large number of experiments in a full-factorial manner provided insights into the progressive tribofilm build-up and wear damage modes and allowed for proposing mechanisms regarding their occurrence. Small deviations from the normal spray angle at long stand-off distances proved to be beneficial for the wear performance of the coatings. The highest friction coefficient and most aggressive wear damage were observed in coatings with a rich coverage of the wear track with a tribofilm. The phase composition of the coatings proved to be the principal contributor in the wear performance.
\end{abstract}

Keywords dry sliding $\cdot$ HVOF - spray angle $\cdot$ tribofilm . WC-Co · wear

Vasileios Katranidis

vasileios.katranidis@surrey.ac.uk

1 Department of Chemical and Process Engineering, University of Surrey, Guildford GU2 7XH, UK

2 Monitor Coatings, 2 Elm Road, Tyne and Wear NE29 8SE, UK

\section{Introduction}

The deployment of WC-Co coatings in wear/corrosion intensive applications has grown the past decades into a well-established industrial practice. Such cermet coatings are typically sprayed via thermal spray methods such as atmospheric plasma spray (APS), high-velocity oxy-fuel (HVOF) and high-velocity air-fuel (HVAF). The latter two processes are generally preferred due to their lower deposition temperatures and ability to generate high-velocity gas streams that ultimately result into dense, hard coatings with minimum thermal decomposition of WC, in an economically viable manner ( $\operatorname{Ref} 1,2)$. Typically, thermally sprayed coatings are deposited on planar or cylindrical parts that allow for a constant spray angle and spray distance as the gun is translated over the part or the part is rotated in front of the gun. However, the drive to abandon toxic electrolytic hard chrome plating practices $(\operatorname{Ref} 3,4)$ has led to an increasingly pressing demand to coat more complex geometries (Ref 5), externally and internally (Ref $6,7)$, and expand the scope of thermally sprayed cermet coatings applications. Coating complex shapes with a lineof-site method, such as thermal spray, entails variations in spray angle, spray stand-off distance (SOD) and effective gun traverse speed over the coated surface. These are referred to as spray kinematic parameters, and they dictate the state of particle impact and heat and mass transfer to the target surface that, in turn, affect directly the coating's properties (Ref 8, 9). Driven by such industrial trends, authors have focused (1) on studying the influence of the spray kinematic parameters on coating characteristics (Ref $5,10-16)$ and (2) to explore the viability of off-line programming of the spray handling robot to follow the target surface, aiming to produce near-net shaped coatings on complex geometries (Ref 17). From the limited literature 
focusing on the effect of spray kinematic parameters, only a few studies exist that examine their effect on wear behavior of the coatings and with conflicting results. Houdkova et al. (Ref 16) evaluated the 3-body abrasion (ATSM G-65) of HVOF WC-Co and $\mathrm{Cr}_{3} \mathrm{C}_{2}-\mathrm{NiCr}$ coatings and reported declining wear resistance with increasing oblique spray angle, whereas Strock et al. (Ref 15) reported improved fretting wear resistance at oblique spray angles, when HVOF WC-CoCr coatings were tested, which is claimed to be due to the better distribution of phases at low spray angles. Moreover, these studies are limited in interpretation, because they focus on the effect of a single kinematic parameter at a time and do not consider the interplay between spray angle and spray distance that have been proven to be significant ( $\operatorname{Ref} 8,9$ ). Thus, the rationale behind this work, which is a continuation of Ref 8 and 9, is to examine the effect, and interplay, of spray angle and spray distance on the tribological properties of the coating and their correlation with basic microstructural and mechanical coating properties. The tribological effects of gun traverse speed will be examined in future work. The gun traverse speed does not influence the state of particle impact (temperature and velocity), but it controls phenomena occurring post-particle impact such as superficial oxidation (Ref 9) and the heat and mass transfer to the coating.

\section{Experimental}

\section{Feedstock Powder, Spray Process, and Experimental Setup}

Steel substrates (SAE 1070) of dimensions of $160 \times 80 \times$ $3 \mathrm{~mm}^{3}$ were coated with a commercial agglomerate sintered powder of WC-17Co mass\% with a size distribution of $(-33+9)(\operatorname{Ref} 18)$. The morphology of the powder particles can be seen in Fig. 1, which is an image from the backscatter electron (BSC) detector in the scanning electron microscope (SEM).

Prior to deposition, the substrates were grit-blasted with alumina particles of $46 \mu \mathrm{m}$ median size at $100 \mathrm{~mm}$ distance and, afterward, cleaned via high-pressure air blasting and mechanical means to remove any remaining grit on the substrate surface. The coating deposition was done using a patented "compact HVOF" process (Ref 19) which comprises an isentropic plug nozzle to accelerate the exhaust gases to supersonic velocities reaching Mach 2.7. The process parameters for the gun were previously optimized in-house using Oseir's SprayWatch system for achieving the best microstructure (indicated by minimum porosity

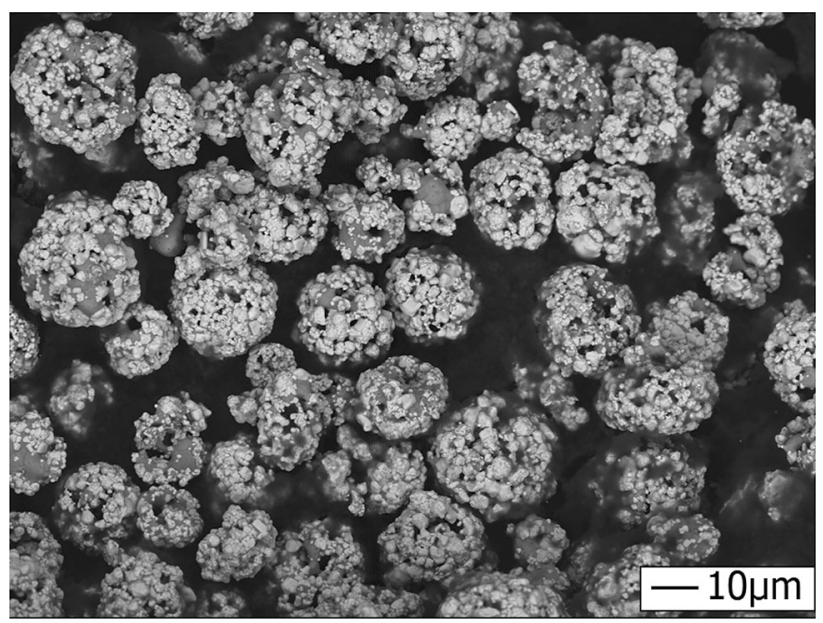

Fig. 1 Starting powder BSC image SEM

Table 1 Mean particle velocity and temperature at 120 and $240 \mathrm{~mm}$ from the nozzle (Ref 8)

\begin{tabular}{|c|c|c|c|}
\hline \multicolumn{2}{|c|}{ Particle velocity } & \multicolumn{2}{|c|}{ Particle temperature } \\
\hline $120 \mathrm{~mm} \mathrm{SoD}$ & $240 \mathrm{~mm} \mathrm{SoD}$ & $120 \mathrm{~mm} \mathrm{SoD}$ & $240 \mathrm{~mm} \mathrm{SoD}$ \\
\hline $860 \mathrm{~m} / \mathrm{s}$ & $630 \mathrm{~m} / \mathrm{s}$ & $1500 \mathrm{~K}$ & $1800 \mathrm{~K}$ \\
\hline
\end{tabular}

and binder mean free path and maximum $\mathrm{WC}$ vol.\%) and the highest microhardness, which occur at $120 \mathrm{~mm}$ spray distance and at $90^{\circ}$ of spray angle.

Twenty coatings have been subjected to dry sliding tests sprayed at four stand-off distances (120, 138, 170 and $240 \mathrm{~mm}$ ) and at five spray angles at each examined spray distance $\left(90^{\circ}, 75^{\circ}, 60^{\circ}, 45^{\circ}\right.$ and $\left.30^{\circ}\right)$. All of the examined samples were sprayed at consistent gun traverse speed of $502 \mathrm{~mm} / \mathrm{sec}$. Average particle velocity and temperature at the boundary spray distances of 120 and $240 \mathrm{~mm}$ are presented in Table 1, as measured by the Oseir's SprayWatch system. The samples have been named (a1 to e4) so that their kinematic conditions can be identified in the correlation graphs. The sample names and respective kinematic conditions can be seen in Table 2, where the wear results are presented.

\section{Dry Sliding Tests}

All the samples were cut, mounted in bakelite and mirrorpolished down to $\mathrm{Ra}<0.2 \mu \mathrm{m}$ prior the dry sliding wear tests at room temperature conditions $\left(20^{\circ} \mathrm{C}, 70 \%\right.$ humidity. A standard tribometer (TRB) manufactured by CSM Instruments (Switzerland) was used with the following parameters: normal load of $10 \mathrm{~N}$, sliding speed of $300 \mathrm{~mm} / \mathrm{s}$ 
Table 2 Specific wear rate and friction coefficient, as well as microstructural measurements (Ref 8,9$)$ for all the examined coatings

\begin{tabular}{|c|c|c|c|c|c|c|c|}
\hline \multicolumn{3}{|c|}{ Coatings' spray parameters } & \multicolumn{2}{|c|}{ Tribology } & \multicolumn{3}{|c|}{ Microstructure } \\
\hline $\begin{array}{l}\text { Sample } \\
\text { name }\end{array}$ & $\begin{array}{c}\text { Stand-off } \\
\text { distance, } \mathrm{mm}\end{array}$ & $\begin{array}{l}\text { Spray } \\
\text { angle, }^{\circ}\end{array}$ & $\begin{array}{l}\text { Specific wear rate, } \times 10^{-7} \\
\mathrm{~mm}^{3} \mathrm{~m}^{-1} \mathrm{~N}^{-1}\end{array}$ & $\begin{array}{l}\text { Average Friction } \\
\text { coefficient, } \mu\end{array}$ & $\begin{array}{c}\mathrm{WC} \\
\text { vol. } \%\end{array}$ & $\begin{array}{l}\text { Microhardness } \\
\text { (HV0.3) }\end{array}$ & $\begin{array}{l}\text { WC retention } \\
\text { index, \% }\end{array}$ \\
\hline a1 & 120 & $90^{\circ}$ & 0.52 & 0.363 & 51.9 & 1365 & 94 \\
\hline $\mathrm{a} 2$ & 138 & $90^{\circ}$ & 0.59 & 0.356 & 49.1 & 1323 & 94 \\
\hline a3 & 170 & $90^{\circ}$ & 1.2 & 0.38 & 49.3 & 1176 & 93 \\
\hline a4 & 240 & $90^{\circ}$ & 2.81 & 0.558 & 48.4 & 795 & 91.7 \\
\hline b1 & 120 & $75^{\circ}$ & 0.57 & 0.421 & 49 & 1337 & 93.8 \\
\hline b2 & 138 & $75^{\circ}$ & 0.49 & 0.367 & 51.3 & 1321 & 93.8 \\
\hline b3 & 170 & $75^{\circ}$ & 1.25 & 0.43 & 50 & 1204 & 92.5 \\
\hline $\mathrm{b} 4$ & 240 & $75^{\circ}$ & 2.14 & 0.538 & 49.8 & 888 & 90 \\
\hline $\mathrm{c} 1$ & 120 & $60^{\circ}$ & 0.82 & 0.394 & 46.1 & 1260 & 93.5 \\
\hline c2 & 138 & $60^{\circ}$ & 1.06 & 0.328 & 46.1 & 1254 & 92.5 \\
\hline c3 & 170 & $60^{\circ}$ & 1.6 & 0.404 & 46.3 & 1180 & 92.2 \\
\hline $\mathrm{c} 4$ & 240 & $60^{\circ}$ & 2.45 & 0.507 & 47.6 & 891 & 91 \\
\hline d1 & 120 & $45^{\circ}$ & 0.91 & 0.348 & 43.9 & 1210 & 92.4 \\
\hline $\mathrm{d} 2$ & 138 & $45^{\circ}$ & 1.04 & 0.418 & 39.1 & 1182 & 91.6 \\
\hline $\mathrm{d} 3$ & 170 & $45^{\circ}$ & 2.06 & 0.42 & 41.4 & 1123 & 91.7 \\
\hline $\mathrm{d} 4$ & 240 & $45^{\circ}$ & 3.23 & 0.538 & 39.7 & 893 & 90 \\
\hline e1 & 120 & $30^{\circ}$ & 1.74 & 0.418 & 32 & 1108 & 89.6 \\
\hline e2 & 138 & $30^{\circ}$ & 1.46 & 0.502 & 37 & 1105 & 87.4 \\
\hline e3 & 170 & $30^{\circ}$ & 2.66 & 0.521 & 38.3 & 1068 & 85.7 \\
\hline e4 & 240 & $30^{\circ}$ & 3.93 & 0.579 & 38.7 & 921 & 88 \\
\hline
\end{tabular}

and total sliding distance of $1000 \mathrm{~m}$. The mild load and relatively short sliding distance were chosen, considering the wide-ranging quality of the examined coatings. Each test was conducted with a new counter-body. Sintered alumina balls (CSM instruments) were selected as a counter-body for the wear tests because of their high nominal hardness (1610 HV0.2) and high contact friction with cermet coatings that results in aggressive wear and limited debris production (Ref 20). The wear track diameter was $6 \mathrm{~mm}$ in all tests. At least two tests were performed for each sample. Before the dry sliding tests, the best and worst coatings (in terms of microhardness) (Ref 8) were tested, separately, at $3000 \mathrm{~m}$ sliding distance. At these preliminary tests, the friction coefficient was continuously monitored, and the wear mass loss was measured every $750 \mathrm{~m}$ to ensure that the wear rate had reached a steady state before $1000 \mathrm{~m}$. Thus, it is safely assumed that all the coatings reach steady wear rate by $1000 \mathrm{~m}$. The mass loss measurements were performed only in the two preliminary wear tests, which are described above. The coefficient of friction (COF) was plotted against sliding distance. All the wear tests were performed at least two times for each coating, including a third time where there was a significant deviation in the mass loss measurement.

\section{Characterization of Samples}

The sample wear volume loss was measured by laser confocal profilometry (ZEISS LSM 700, USA). The data were then converted to specific wear rate (defined as the wear volume per unit sliding distance $\times$ unit normal load). For the volume loss measurements, at least five independent profiles of the wear track were evaluated for each coating. The product of the areas under the mean line of the profiles and the length of the wear track were used to calculate the corresponding volume loss of the wear track. Subsequently, the volume loss measurements were averaged for each coating. The wear scars were observed by optical microscopy (ZEISS Axiophot, USA) and scanning electron microscopy (JEOL, JSM-7100F, USA) equipped with a secondary electron detector (SEC), backscatter electron detector (BSC) and energy-dispersive analysis (EDS) so that their macroscopic and microscopic features can be evaluated. The SEM images were captured at $15-20 \mathrm{kV}$ of acceleration voltage and at $8 \mathrm{~A}$ probe current. The XPS measurements were carried out by K-APLHA+, Thermo Scientific photoelectron Spectrometer (USA) with monochromatic $\mathrm{Al} \mathrm{K} \alpha(1486.6 \mathrm{eV})$ x-ray source. All binding energies were calibrated by using $\mathrm{C} 1$ s peak with a 
fixed valued of $285 \mathrm{eV}$. The x-ray photoelectron spectra (XPS) analysis was conducted on the wear tracks of selected coatings, and the spot size of the x-ray was adjusted to the width of the wear tracks each time. Quantification of the XPS results is not possible due to the variable tribofilm coverage of tribofilm between the examined coatings. The error bars in the results of this work indicate the standard error of measurement.

\section{Results and Discussion}

\section{Dry Sliding Tests and Morphology of the Wear Tracks}

Table 2 presents the specific wear rate (SWR) and the average coefficient of friction (COF) as well as the microhardness, WC vol.\% and WC retention index (Ref $21)$ for each coating with its respective name and kinematic conditions.

The microstructural results in Table 2 are discussed and correlated with the spray kinematic parameters in detail in previous works (Ref 8, 9). The stand-off distance of $120 \mathrm{~mm}$ and spray angle of $90^{\circ}$ are the optimum conditions in terms of minimum in-flight heating of particles and maximum normal component of velocity at impact (Ref 8). As such, they result in optimum microhardness, porosity and WC density and thus are expected to show minimum wear damage under the mild wear conditions employed in this work. In light of that, the wear performance of coating a1 $\left(90^{\circ}, 120 \mathrm{~mm}\right)$ can be used as a reference point regarding the effects of spray distance and spray angle. The specific wear rate of coating a1 is in good agreement with Ref 22-26 where the sliding wear behavior of $\mathrm{HVOF} / \mathrm{AF}$ WC-12Co is examined and with Ref 27 and 28 where WC$\mathrm{FeCrAl}$ and $\mathrm{WC}-10 \mathrm{Co} 4 \mathrm{Cr}$ coatings are examined under similar conditions. Moreover, coating a1 appears to have the lowest average COF as well.

In Fig. 2, it is seen that coatings sprayed at distances of 120 and $138 \mathrm{~mm}$ behave similarly in terms of SWR throughout the examined spray angles. The angle inclination from $90^{\circ}$ to $75^{\circ}$ does not seem to affect the SWR at these spray distances. Beyond $75^{\circ}$, a notable and progressive increase in the specific wear rate is observed up to the spray angle of $30^{\circ}$. At $170 \mathrm{~mm}$ of spray distance, all the coatings present clearly elevated coefficients of wear from the shorter spray distances, at all spray angles. The rise associated with oblique spray angle is mild between $90^{\circ}$ and $75^{\circ}$ (5\% increase) and rises with a steady rate of $30 \%$ per iteration of spray angle until $30^{\circ}$. The deterioration of coatings with increasing spray distance at $240 \mathrm{~mm}$ is evident where again, irrespective of spray angle, all the concerned coatings present significantly higher SWR than the ones sprayed at shorter spray distances. Moreover, the influence of spray angle at $240 \mathrm{~mm}$ is considerably different than shorter spray distances. Unexpectedly, there is a clear improvement in the wear resistance occurring from $90^{\circ}$ (a4) to $75^{\circ}$ (b4) of spray angle, where the SWR is reduced by $23 \%$ (Fig. 2). From $75^{\circ}$ and onward, the SWR is increased steadily with increasingly oblique spray angles at $15-30 \%$ per angle iteration. Coating e4 exhibits the worse wear resistance with a SWR more than six times higher than coating a1. The reasons for the improvement in SWR at $75^{\circ}$ can be traced back to the microstructure (Ref 9) and mechanical properties (Ref 8) of the concerned coatings and will be discussed thoroughly later in this text.

Although coatings sprayed at 120 and $138 \mathrm{~mm}$ behave similarly in terms of wear volume loss, it is clear that, for the rest of the examined spray distances, the effect of spray distance is more severe than the effect of decreasing spray angle on the wear behavior of coatings. The effect of spray distance is most severe at less oblique spray angles like $90^{\circ}$ and $75^{\circ}$ where SWR is more than doubled with each SOD iteration after $138 \mathrm{~mm}$. As the spray angle gets more oblique, the relative effect of spray distance on SWR is milder but still greater that the effect of spray angle. It is also interesting that the standard error of measurement is markedly increased as the spray distance is increased (Fig. 2). This indicates a larger scatter among the volume loss measurements that were made on the coatings of longer SOD. Ultimately, the increased scatter of measurement can be explained from the large pits that are increasingly present in the wear track of coatings sprayed at long spray distances.

Figure 3 includes a collection of images of the wear tracks taken with the optical microscope aiming to compare the macroscopic morphological features of the wear tracks between the tested coatings. The wear tracks appear less evident on coatings sprayed at short spray distances and near-normal spray angles (a1, b1, a2, b2). At these conditions, minimum wear products are produced and some isolated darker areas are seen on the wear track. As the spray distance is increased and the spray angle gets more oblique, the frequency of pits and darker material surviving on the wear track is drastically increased. In addition, at 170 and $240 \mathrm{~mm}$ of spray distance large spallations and pits can be identified on the wear tracks. EDS and XPS analysis showed that the darker areas on the wear tracks are composed of mainly $\mathrm{Co}$ and $\mathrm{W}$ oxides and some traces of the $\mathrm{Al}_{2} \mathrm{O}_{3}$ counter-body. Such formations are commonly found on wear tracks of cermet materials that were worn in air, and they are usually referred to as tribofilm or transfer film. Looking at Fig. 3, it can be seen that coatings sprayed at angles of $30^{\circ}$ and at distances longer than $120 \mathrm{~mm}(\mathrm{e} 2$, e3, e4) have almost all of their area covered by a layer of tribofilm. The same applies for all the coatings sprayed at 
Fig. 2 Specific wear rate of all coatings vs. spray angle

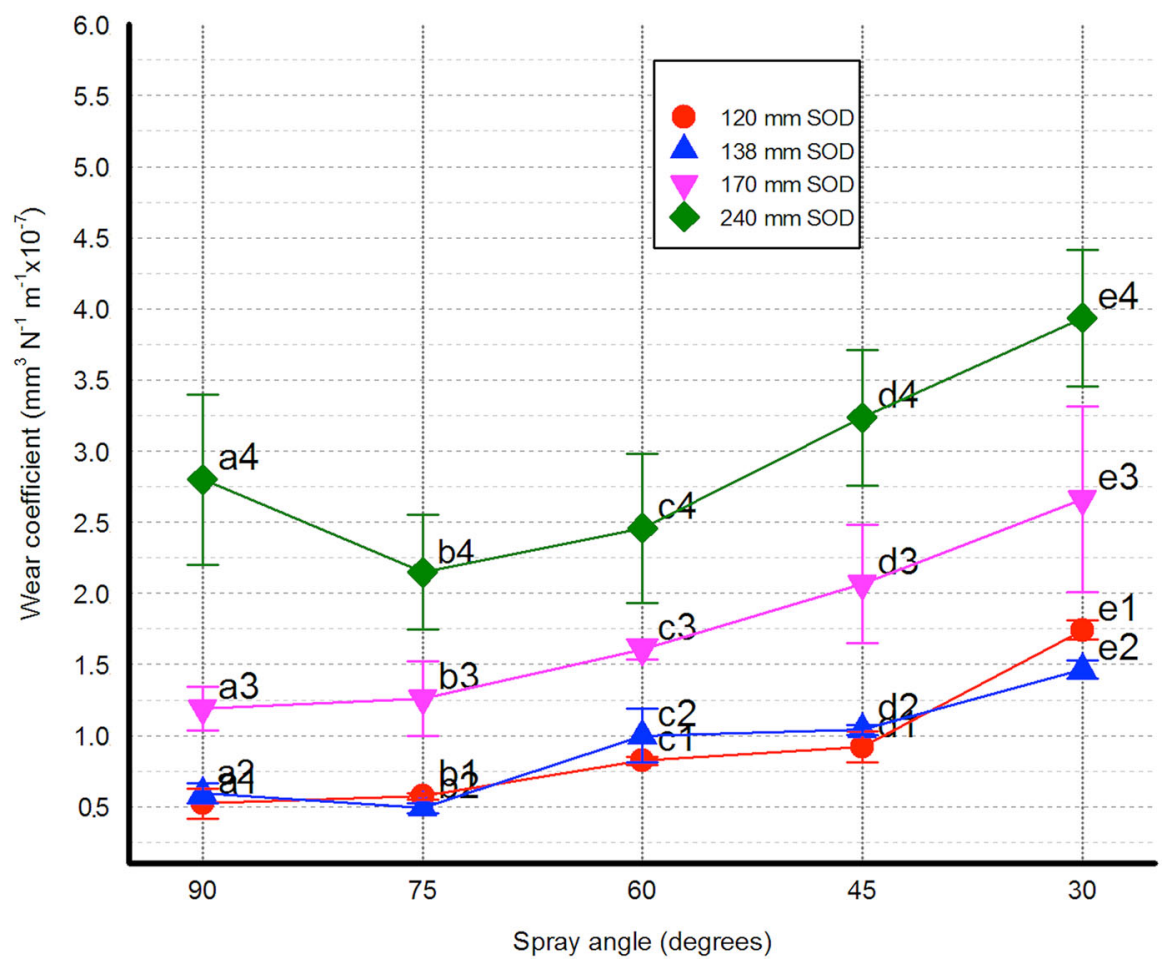

$240 \mathrm{~mm}$, irrespective of spray angle (a4, b4, c4, d4, e4). It is established that the produced tribofilm originates from the oxidation, compaction/deformation and sintering of wear debris that has been trapped between the sliding surfaces and has been smeared over the wear track, intruding in any surface cavity that resulted from preceding material loss (Ref 22, 29-33). However, the effect of tribofilm to the wear behavior of cermet coatings is still unclear. Certain authors support that it has lubricating properties that stem from the presence of certain oxides that are generated from the heat of friction (Ref 34-36) and contributes to lowering the COF, while others (Ref 37,38 ) demonstrate that COF is, in fact, elevated in the presence of tribofilm.

\section{Microstructure of Wear Tracks}

In Fig. 4, sites from sample a1 $\left(90^{\circ}, 120 \mathrm{~mm}\right)$ are seen. Figure 4(a), (b), (c) and (d) is taken at a $70^{\circ}$ angle inclination of the wear track, in order to emphasize the third dimension of the surface morphology. In Fig. 4(a), the wear track boundary is featured where the effect of binder extrusion that occurs during dry sliding is evident by comparing the prominent WC grains inside the wear track with the smoother surface finish outside of it. The surface finish of the coating outside of the wear track can be seen in better detail in Fig. 4(g), where mild unidirectional traces of the polishing abrasive can be detected. In addition, due to the smooth surface finish, the WC grain boundaries are not clearly distinguished from the surrounding binder. Some inconsistencies on the polished coating surface are identified, originating either from WC pull-outs during the grinding and polishing steps, or from preferentially excavated weakly bonded splat boundaries, yet they occur rarely. The WC grains in the wear track seem to be better defined due to the preferential removal of the surrounding binder, leaving them more exposed to the sliding counter-body. In Ref 39 , it is shown that there is plastic flow in the binder at significant depth below the sliding interface because all of the plastic stain generated by the sliding motion is accommodated exclusively by the binder. In turn, the plastic flow of binder relaxes any residual stress (Ref 39), which, along with the depletion of binder locally to the surface via extrusion, renders the superficial WC grains more susceptible to pull-out and fracture. The carved morphology that results from the extrusion of the binder can be seen in better detail in Fig. 4(b), (c) and (d). Coating a1 exhibited mainly sites of isolated WC grain pull-out (Fig. 4c). Neighboring WC grains that have been pulled out create pits that can later be joined under the repetitive wear, and evolve into larger pits (Fig. 4d). In addition, there are some sites with large pits spanning close to $10 \mu \mathrm{m}$ and filled with compacted wear debris (Fig. 4e). It is probable that the origin of the larger pits is via the gradual enlargement and merge of smaller pits as described above; alternatively, they could be formed via the joining of subsurface cracks and spallation of larger pieces of the coating that contain both WC grains and their 


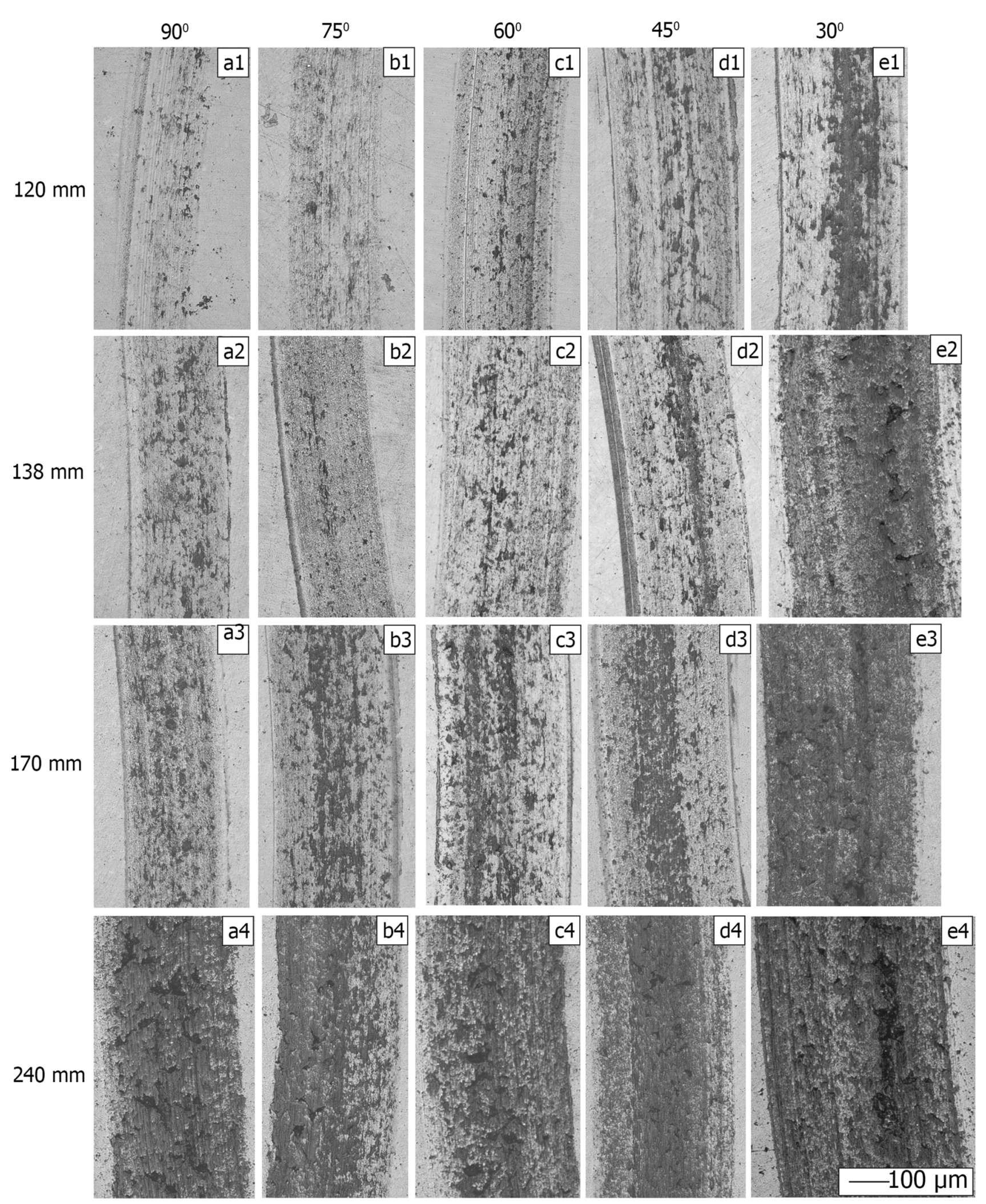

Fig. 3 Optical microscopy macroscopic images of the wear tracks of all tested coatings 
Fig. 4 SEM images of coating a1 $\left(90^{\circ}, 120 \mathrm{~mm}\right)$ (a) wear track boundary, (b) wear track featuring prominent $\mathrm{WC}$ grains and Co-binder extrusion, (c) wear track featuring isolated WC pull-outs, (d) wear track featuring WC pull-outs that joined to form a larger pit, (e) BSC image featuring larger pit filled with wear debris with visible grooves, (f) BSC image featuring surface trans-granular and inter-granular cracks, (g) SEC image of the polished coating surface, outside of the wear track, showing remote, small pits
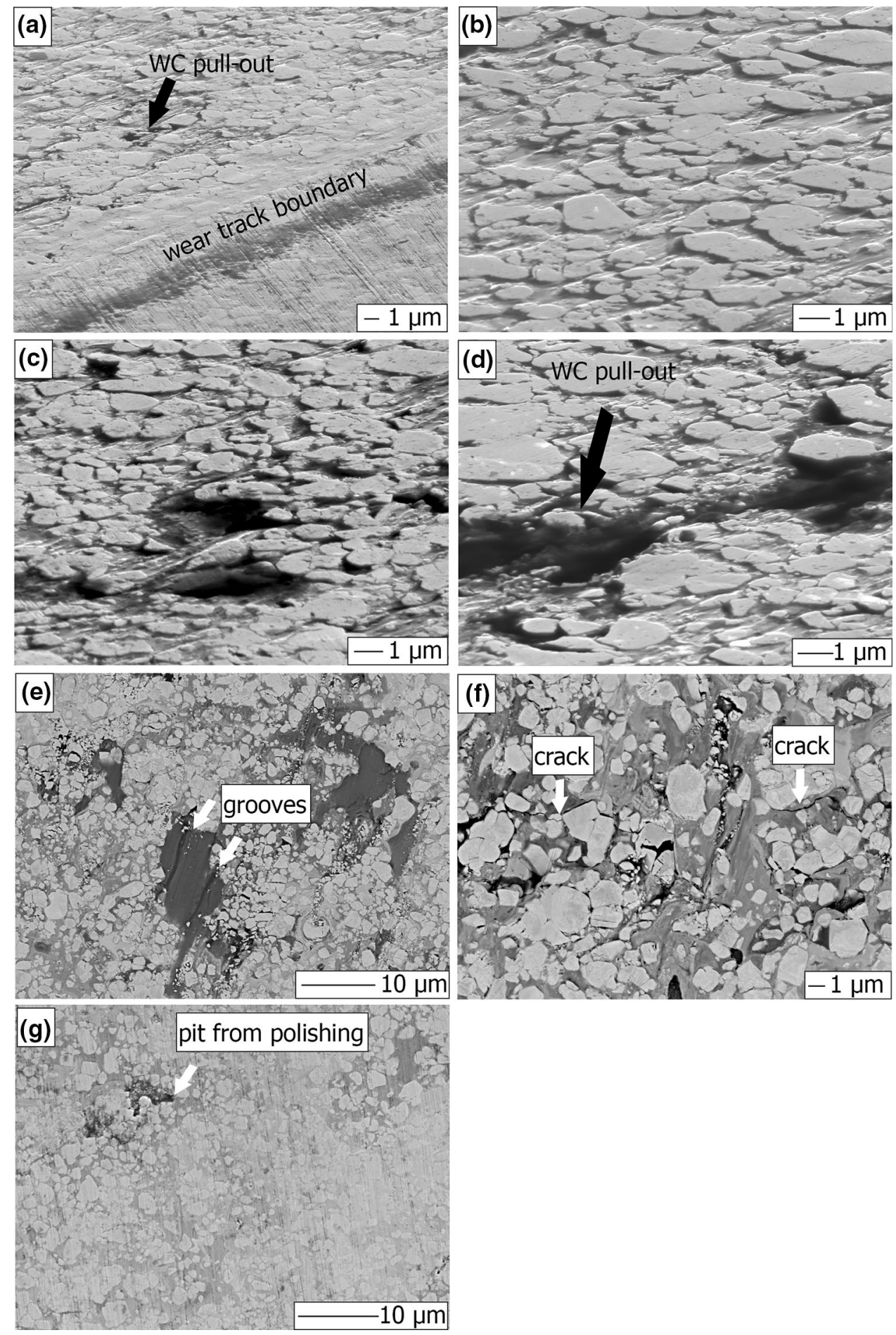

surrounding binder. Moreover, the fact that such craters (Fig. 4e) approach the expected size of a splat suggests that, in part, they could be due to individual splat delamination, which is commonly observed in such wear conditions (Ref 24). Figure 4(f) shows such sites where small cracks are seen to progress inter-granularly and transgranularly. Such surface cracks have also been observed in previous work that examines dry sliding of cermet coatings (Ref 22, 27, 40).

The fact that trans-granular cracks exist indicates (1) the high bond strength of the binder-WC couple and (2) the adequately high toughness of the binder phase that makes the fracture of WC preferable to the inter-granular propagation of the crack. Surface cracks like the ones seen in 
Fig. 4(f) are relatively rare in coating a1. The visible grooves on the surface of the compacted wear debris that has intruded into the pit in Fig. 4(e) indicate the plasticity of the tribofilm that is formed at this site and the size of the abrasive WC that plowed it. Even though the coating surface outside the wear track (Fig. $4 \mathrm{~g}$ ) is not perfectly smooth and demonstrates remote pits (owning to pull-outs during the grinding/polishing stages), there are no cracks on the coatings surface, like the ones seen in Fig. 4(f).

Besides WC pull-outs, two other primary mechanisms of superficial WC removal on the wear track have been observed in coatings sprayed at short spray distances and near-normal spray angles (a1, b1, a2, b2). The first one concerns the survival of regions with very high ratio of WC to Co-binder (WC-clusters) in the coating that results in inadequate support due to the scarce surrounding binder. These WC-clusters originate from structure of the starting particles (Fig. 5a), where they are initially formed in the agglomerating and sintering stages of the powder production. It has been demonstrated (Ref 9) that such WCclusters are often retained in the coating microstructure (Fig. 5b) and now it is seen that they are favorable points for the initial removal of unsupported carbide grains during sliding (Fig. 5c). Finally, some surface WC grains fracture due to overwhelming local contact stresses. Such fractures lead to the progressive detachment and removal of the fragments due to not adequate support (Fig. 5c) and are promoted when loose WC grains act like third-body abrasives during sliding.
Oblique spray angles at short SODs $(120,138 \mathrm{~mm})$ showed significantly more cracking on the surface of the wear track (Fig. $6 \mathrm{~b}$ and d) than coating a1. This is reflected to more pits (Fig. 6a) that could originate from individual superficial splat removal which is anticipated since the inter-splat bonding is expected to be compromised at oblique deposition angles due to the associated changes in particle velocity vectors (Ref 8,16 ) (Fig. 6a and c). The cracks continued to be trans-granular and inter-granular up to the coatings sprayed at $45^{\circ}$ (Fig. 6b). Coatings sprayed at $30^{\circ}$, at short spray distances, showed evidence of only inter-granular cracks (Fig. 6d) which suggests a significant change in the toughness of the binder phase, inter-splat cohesion, or both. Moreover, looking at coating e1 $\left(30^{\circ}\right.$, $120 \mathrm{~mm}$ ) in Fig. 6(c), a continuous zone of tribofilm appears to form along the wear track. This formation provides insight into the early stages of tribofilm build-up and, ultimately, into the manner with which it covers the whole wear track surface on coatings sprayed at longer distances (Fig. 3e2, e3, a4, b4, c4, e4). The fact that the tribofilm zone in Fig. 6(c) is continuous along the trajectory of the wear track suggests that after a spallation has occurred, the wear damage is accelerated on the succeeding area, locally, along the direction of the sliding motion. This is expected since any debris that is produced will start abrading first the site most adjacent to it, in the sliding direction. The first phase of three-body abrasion caused by as-produced wear debris will be the most severe since any WC grains participating will not have had the chance to
Fig. 5 (a) BSC SEM image of a powder particle featuring WCclusters, (b) SEC SEM image of WC-clusters in the microstructure of coating a1, (c) SEC SEM image of the wear track of coating al featuring WC loss via fracture and cluster dismantling
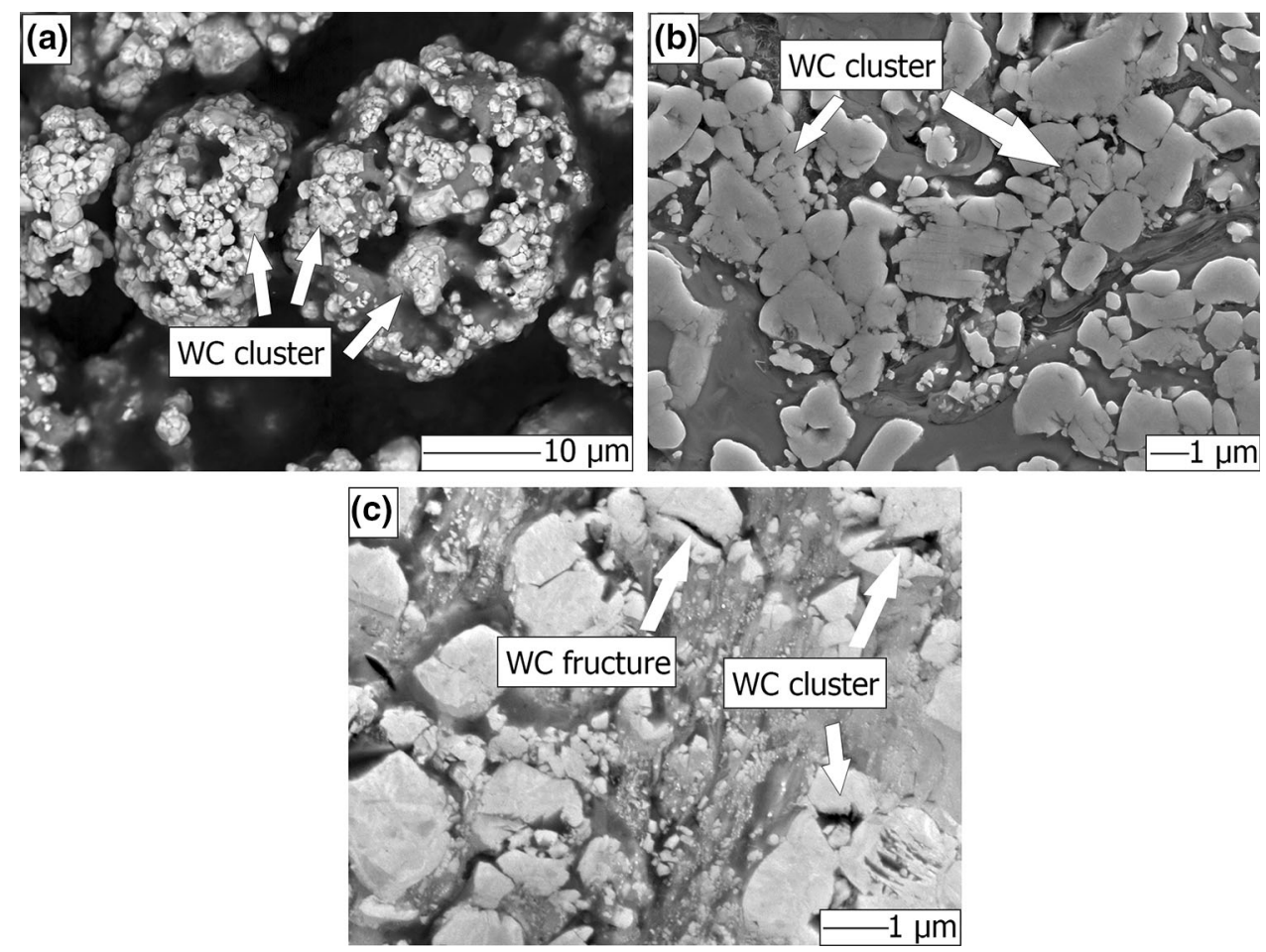
Fig. 6 SEM images of coatings d1 and e1 (a) view of the wear track of coating d1, (b) BSC image, trans-granular and intergranular cracks on the surface of coating $\mathrm{d} 1$, (c) view of the wear track of coating e1, (d) intergranular cracks on the surface of coating e1
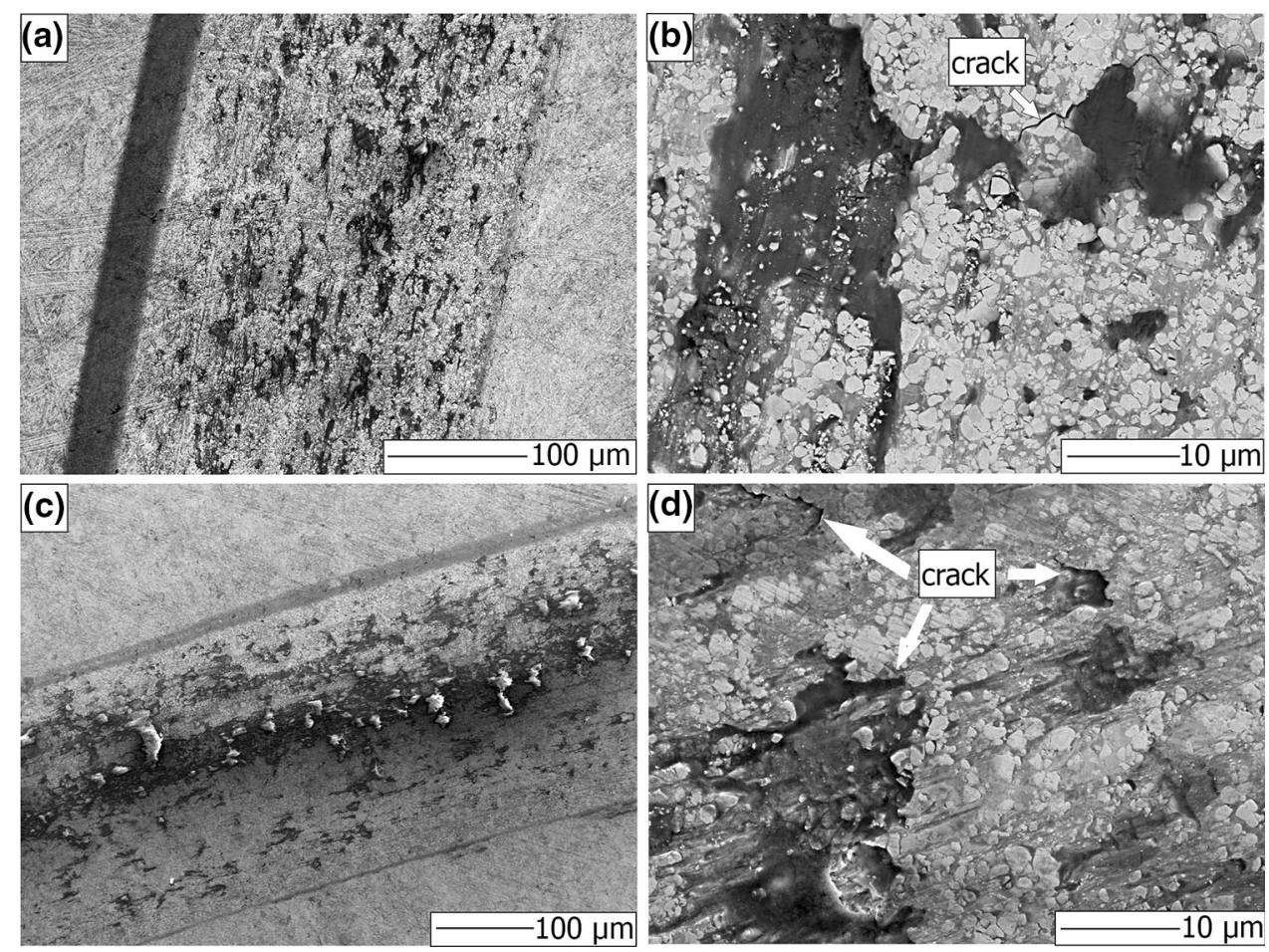

fracture, therefore being at their largest size. Larger WC grains are more aggressive third-body abrasives than smaller ones (Ref 35). In that manner, discrete spallations on the wear track area will gradually become elongated along the direction of sliding (Fig. 6a and c) until they reach a critical density and eventually join-up to form a continuous tribofilm zone (Fig. 6c). It is also interesting that the formation of a continuous accelerated wear zone filled with tribofilm at coating e1 $\left(30^{\circ}, 120 \mathrm{~mm}\right.$, Fig. 6c) coincides with the markedly intensified SWR of this coating, compared with the coatings sprayed at the same spray distance (Fig. 2a1, b1, c1 and d1). Lastly, even at coatings e 1 and e $2\left(30^{\circ}, 120\right.$ and $138 \mathrm{~mm}$ respectively) there is evidence of single WC grains fracturing and pullouts.

Figure 7 presents images from coatings sprayed at $90^{\circ}$, at different spray distances. Figure 7(a) (coating a2, $90^{\circ}$, $138 \mathrm{~mm}$ ) shows a significant increase in the density and size of pits and wear debris remnants on the wear track in comparison with coating a1 at only $18 \mathrm{~mm}$ increase in the spray distance. Figure 7(b) focuses on a site with not much tribofilm coverage on the wear track of coating a3 $\left(90^{\circ}\right.$, $170 \mathrm{~mm}$ ) and both surface cracks and WC pull-outs can be seen suggesting that the same underlying mechanisms of spallation as at shorter SODs are still active and responsible for material loss. The cracks are trans-granular and inter-granular. Moreover, the limited surviving tribofilm in Fig. 7(b) has engulfed some crushed, coarse WC grains of size close to $1 \mu \mathrm{m}$. This type of WC debris contributes to three-body abrasion when surrounding tribofilm is smeared over the coating surface by the sliding counter-body. Conversely, in Fig. 7(c), a site from the same coating (a3) that is fully covered by tribofilm is examined. It can be clearly seen that (1) beyond the micron-sized crushed WC grains, there is a large amount of nano-WC with a good distribution in the tribofilm and (2) a wavy surface pattern appears on the tribofilm that extends in a direction normal to the sliding motion. Similar wavy surface features on tribofilms have been observed by Ref 28 and have been associated with near-surface plastic deformation caused by the shear stresses between the sliding interfaces and superficial oxidation (Ref 36$)$.

The features of the tribofilm presented in Fig. 7(c) are substantially different from the ones seen in Fig. 7(b) even though they both originate from the same coating. Their differences can be explained by their time of formation during the sliding test and how this shaped the local conditions in each case. Initially, surface pits on the wear track act as favorable points of tribofilm formation because they trap effectively any wear debris which is smeared over them. This is the case seen in Fig. 7(b), where the tribofilm is protected from intense plastic shearing by the protruding edges of the surface pit it lies in. This early-stage tribofilm appears ductile and shows surface grooves as well as trapped abrasive WC in streams which denote the sliding direction. On this basis, Fig. 7(b) features a site which is formed late with respect to the total wear test duration and did not experience prolonged sliding wear. Conversely, the 
Fig. 7 SEM images of coatings a2, a3, a4, (a) pits on the wear track on coatings a2 $\left(90^{\circ}\right.$, $138 \mathrm{~mm}$ ), (b) BSC image, intergranular and trans-granular cracks on the surface of coating a3 $\left(90^{\circ}, 170 \mathrm{~mm}\right),(\mathrm{c})$ BSC image featuring nano-WC debris and superficial waves on the tribofilm of coating a3, (d) image taken with a tilted sample (700) view of the wear track of coating a $4\left(90^{\circ}\right.$, $240 \mathrm{~mm}$ ) featuring nearcomplete tribofilm coverage and a massive spallation, (e) image taken with a tilted sample (700) view of large pit on coating a4, (f) BSC image featuring brittle fracture and spallation of tribofilm on coating a4
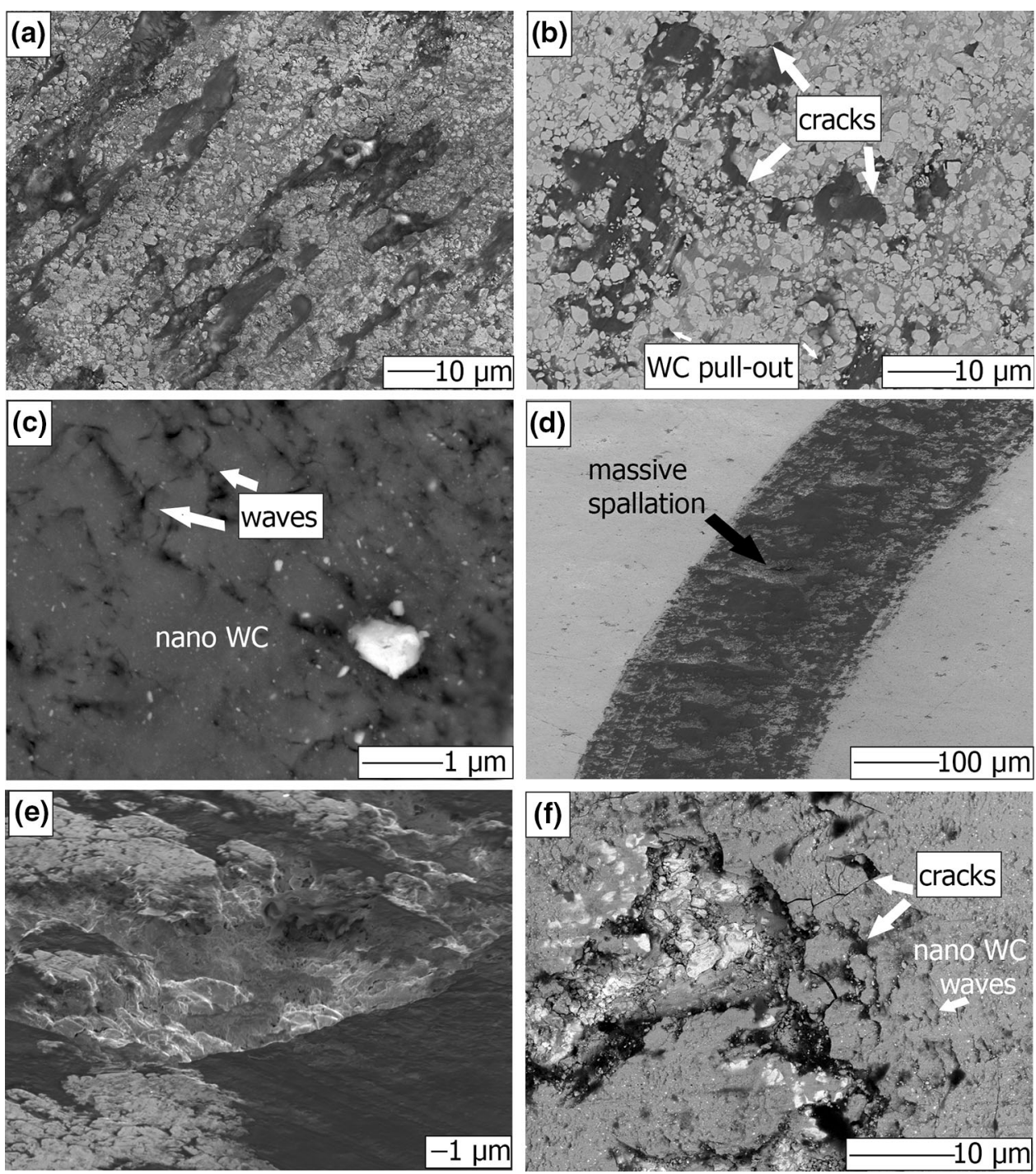

tribofilm in Fig. 7(c) was formed at an earlier stage during the wear test. The extra time under wear led to progressive exposure of the tribofilm to intense plastic shearing and milling of the WC debris down to nano-WC. The good distribution of the nano-WC in the tribofilm (Fig. 7c) is evidence of the extended deformation and mixing they have undergone in the tribofilm, under the repetitive passes of the counter-body. Longer dwell time under sliding wear led to an increase in the thickness of the tribofilm via buildup of additional debris and loss of any protection provided by local conditions in individual pits. In turn, a thick enough tribofilm was able to accommodate the shear stresses with near-surface, local deformation that led to out-of-plane extrusion of tribofilm giving rise to the wavy pattern seen in Fig. 7(c) and (f). The same tribofilm characteristics (nano-WC and wavy surface patterns) are seen on all coatings that present excessive amounts of tribofilm on the wear tracks (Fig. 3 coatings a4, b4, c4, d4, e4, e2, e3) suggesting their extended time under wear.

Figure 7(d) features a low magnification of coating a4 $\left(90^{\circ}, 240 \mathrm{~mm}\right)$ where an almost complete coverage of the tribofilm layer is evident, along with sites of large spallations. Spallation sites can be seen in further detail in Fig. 7(e) and (f). Figure 7(d) and (e) are images from the secondary electron detector in the SEM and as such, only the surface morphology information is captured. On the contrary, Fig. 7(f) is an image from the backscatter electron detector (BSC) of such a site, in which additional information on the structure and composition of the tribofilm can be obtained. Specifically, it is revealed that the tribofilm fractures in a brittle manner and spalls off exposing the underlying coating and in that way large surface pits are created. Additionally, further cracking of the underlying coating is possible as a crack seen in the 
center-left part of Fig. 7(f) appears to extend inside the exposed coating. Brittle tribofilm spalling is consistent over all the coatings that are sprayed at $240 \mathrm{~mm}$ of spray distance $(\mathrm{a} 4, \mathrm{~b} 4, \mathrm{c} 4, \mathrm{~d} 4, \mathrm{e} 4)$ and is also observed to a lesser degree, on the rest of the coatings that exhibit excessive amounts of tribofilm (e2, e3).

Figure 8 shows a large pit that is filled with tribofilm from coating b2 $\left(75^{\circ}, 138 \mathrm{~mm}\right)$. The difference in toughness, of the tribofilm in Fig. 8 with the tribofilm seen in coating a4 (Fig. 7f), is remarkable, the former is ductile enough to exhibit grooves made by coarse WC abrasives (Fig. 8b), while the latter fractures in a brittle manner. As discussed earlier, the size and distribution of the WC abrasives is an indicator of the time of creation of the tribofilm as well as its local environment. Similarly to the wear debris seen on the rest of the coatings sprayed at short distances and near-normal spray angles, on coating b2 (Fig. 8, $75^{\circ}, 138 \mathrm{~mm}$, tough tribofilm) (1) WC grains are mostly in the submicron range but clearly larger than the nano-WC seen on coating a4 (Fig. 7f, $90^{\circ}, 240 \mathrm{~mm}$, brittle tribofilm) and (2) they are not evenly distributed in the tribofilm.

To some degree, it is surprising that coatings that present thick tribofilm coverage (coatings a4, b4, c4, d4, e4, e2, e3) show signs of plastic deformation (wavy surface pattern) and brittle behavior (cracks and spallations) at the same locations (Fig. 7f). In order to probe into the reasons for this two-faced behavior, cross sections of the wear tracks were examined. Figure 9 presents cross-sectional images of the tribofilms of coating a1 $\left(90^{\circ}, 120 \mathrm{~mm}\right.$, Fig. 9a), a4 $\left(90^{\circ}, 240 \mathrm{~mm}\right.$, Fig. 9b) and e $4\left(30^{\circ}, 240 \mathrm{~mm}\right.$, Fig. 9c and d), which are perpendicular to the direction of sliding. Coatings a4 and e4 represent the extreme cases of stand-off distance and spray angle, respectively. These coatings show almost complete coverage of tribofilm (Fig. 3) and evidence of brittle behavior, as seen in Fig. 7(f). As observed in the surface images, micron-sized loose WC grains are clearly seen trapped in the tougher tribofilm (Fig. 9a), whereas the brittle tribofilms (Fig. 9b and c) show a more homogenous structure where individual
WC grains are very rarely identified. Figure 9(d) is a backscatter image of the tribofilm of coating e4 $\left(30^{\circ}\right.$, $240 \mathrm{~mm}$ ) that can discriminate against regions of different atomic weight. It is seen that the homogenous structure of the brittle tribofilm is, in fact, composed of sintered and compacted grains that do not exceed $100 \mathrm{~nm}$ in size, similar to what is reported in Ref 32. Moreover, a subsurface crack is seen to propagate through the thickness of the tribofilm. It seems that the brittle behavior of the tribofilm stems from combination of (1) its nano-crystallized structure, (2) low cohesion as a result of imperfect sintering and smearing at its formation and (3) increase in thickness more than a few microns so that the subsurface shear stresses that exist within it become significant. Moreover, Fig. 9(e) features the same site as Fig. 9(d) but with a lower magnification, allowing for a subsurface crack in the underlying coating to appear. Such cracks propagate progressively during the wear test and are precursors to largescale material removal (fatigue failure).

EDS analysis on tribofilms on all coatings showed similar results with oxygen being the main constituent at $45-60$ at. $\%, \mathrm{Co}$ at $15-20$ at. $\%, \mathrm{~W}$ at $10-15$ at. $\%, \mathrm{C}$ at 2-5 at.\% and varying traces of $\mathrm{Al}$ at 2-13 at.\%. The aluminum detected originates from wear debris of the $\mathrm{Al}_{2} \mathrm{O}_{3}$ counter-body that has transferred and mixed with the tribofilm along the sliding process. The varying degrees of $\mathrm{Al}$ that was detected on the wear tracks did not appear to be correlated with the wear performance of the coatings, nature of tribofilm, or the spray kinematic parameters. The apparent inconsistency in the measured $\mathrm{Al}$ is attributed to two factors. First, due to the high sensitivity of the EDS point measurement to randomly occurring $\mathrm{Al}$ fragments, lying within the interaction volume of the Electron beam. Such individual alumina fragments can be clearly seen in Fig. 10, where discrete bright spots are identified in the EDS map of Al K. Secondly, inconsistencies in the measurement can be caused by the surface potential rise of the examined tribofilm layer, due to its nonconductive nature (Ref 41).
Fig. 8 SEM BSC images of coating b2 $\left(75^{\circ}, 138 \mathrm{~mm}\right)$ featuring (a) a site of early tribofilm formation and (b) details of individual grooves made my WC abrasive particles

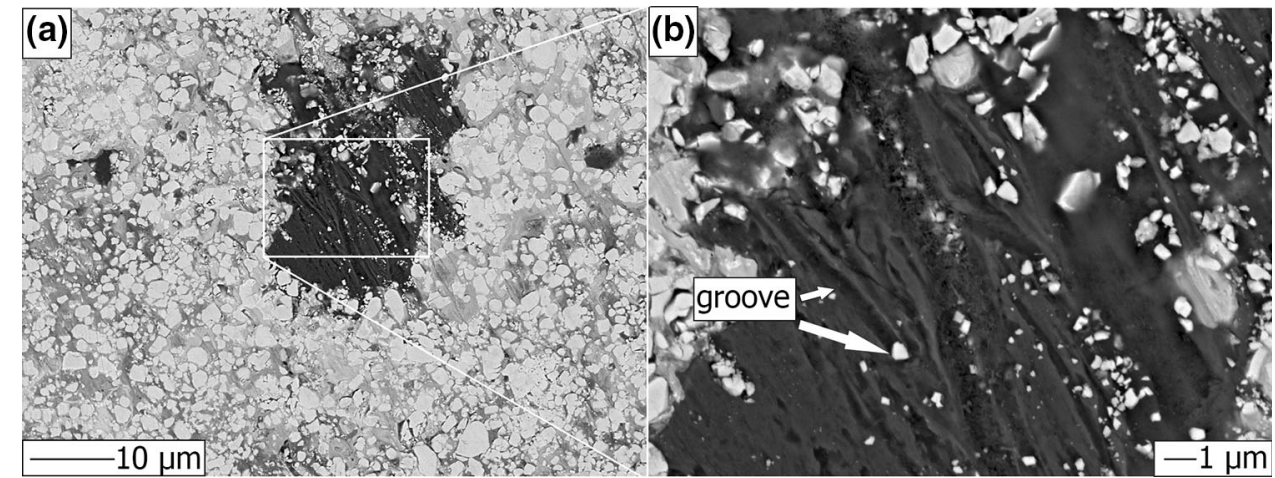


Fig. 9 Cross-sectional SEM images of tribofilms on (a) coating a1 $\left(90^{\circ}, 120 \mathrm{~mm}\right)$, (b) coating a4 $\left(90^{\circ}, 240 \mathrm{~mm}\right)$, (c) coating e $4\left(30^{\circ}, 240 \mathrm{~mm}\right)$ and (d) BSC image of tribofilm on coating e4 $\left(30^{\circ}, 240 \mathrm{~mm}\right)$, (e) BSC image of tribofilm on coating e4 $\left(30^{\circ}, 240 \mathrm{~mm}\right)$ featuring subsurface cracks in the tribofilm and coating
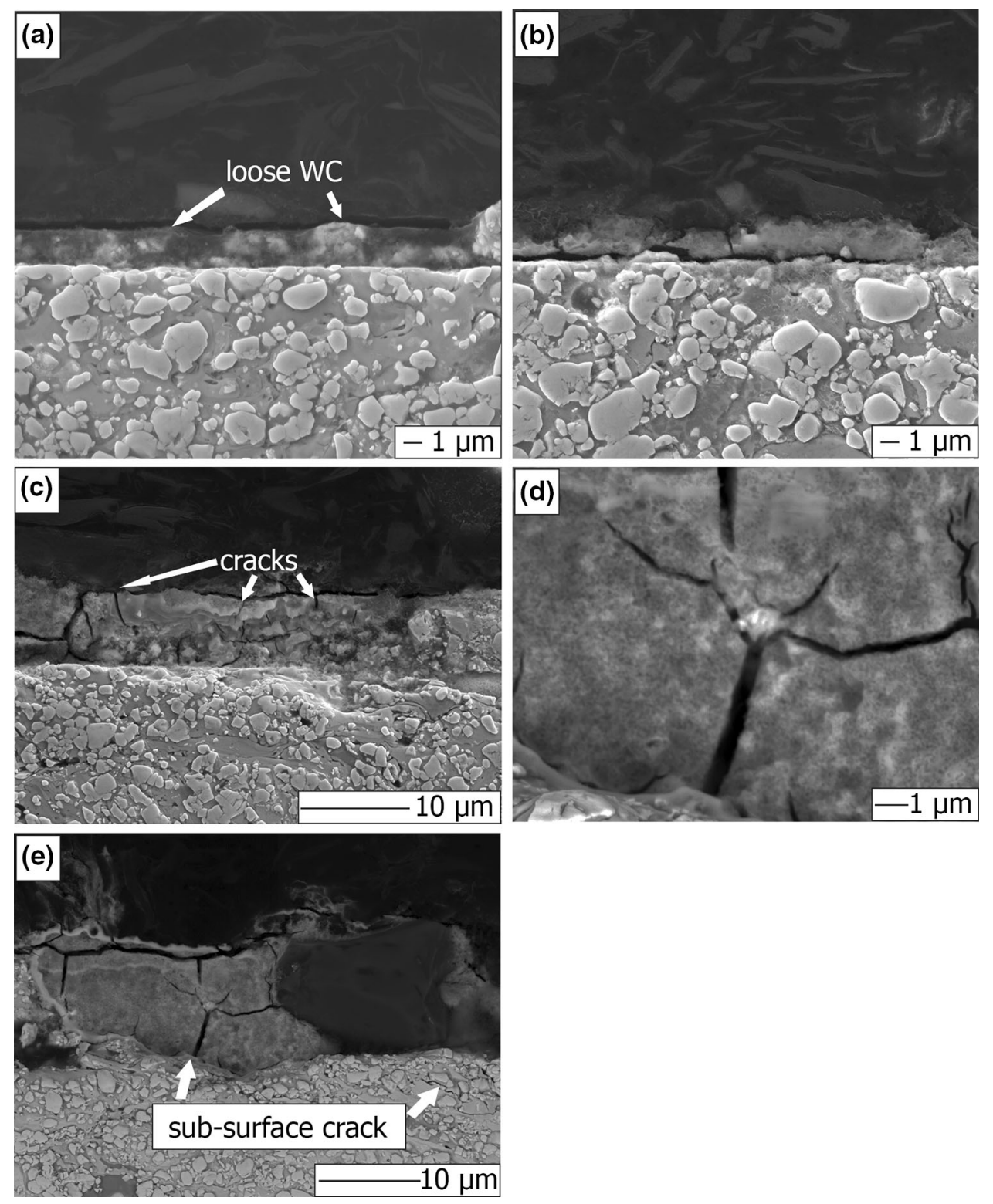

Figure 10 presents surface and cross-sectional EDS maps of tribofilm sites of coating e $4\left(30^{\circ}, 240 \mathrm{~mm}\right.$, brittle tribofilm) and a1 $\left(90^{\circ}, 240 \mathrm{~mm}\right.$, tough tribofilm) where the spatial occurrence of the detected elements can be seen. All of the oxygens are located in the tribofilms along with lower concentrations of $\mathrm{Co}$ and $\mathrm{W}$, which suggest that the measured $\mathrm{O}$ is captured in oxides of the participating elements Co and W. The spatial occurrence of the detected elements appears to be similar in both tribofilms (tough and brittle) in Fig. 10. These observations are in good agreement with relevant literature which supports that tribooxides of $\mathrm{WO}_{3}(\operatorname{Ref} 32,37)$ and $\mathrm{CoWO}_{4}(\operatorname{Ref} 25,29-31)$ are produced during the wear process.

The existence of the proposed oxides $\left(\mathrm{WO}_{3}\right.$ and $\mathrm{CoWO}_{4}$ ) in the tribofilm is confirmed by XPS study of the wear tracks. In Fig. 11, W4f and Co2p spectra of the wear tracks of coatings a1 $\left(90^{\circ}, 120 \mathrm{~mm}\right), \mathrm{a} 4\left(90^{\circ}, 240 \mathrm{~mm}\right)$ and e4 $\left(30^{\circ}, 240 \mathrm{~mm}\right)$ are presented. These coatings are selected because they correspond in the boundary conditions of the kinematic parameters studied. In the W4f spectra, four peaks are identified in all the examined wear tracks, the $\mathrm{W}_{4} \mathrm{f}_{7 / 2}(31.3 \mathrm{eV})$ and the $\mathrm{W} 4 \mathrm{f}_{5 / 2}(33.4 \mathrm{eV})$ from $\mathrm{WC}$ and $\mathrm{W}_{4} \mathrm{f}_{7 / 2}(35.3 \mathrm{eV})$ and the $\mathrm{W}_{4} \mathrm{f}_{5 / 2}(37.4 \mathrm{eV})$ from $\mathrm{WO}_{3}$ or $\mathrm{CoWO}_{4}$ (Ref 42). In the Co2p spectra, the two main peaks at 780.7, $796.5 \mathrm{eV}$ represent the Co $2 \mathrm{p}_{3 / 2}$ and Co $2 \mathrm{p}_{1 / 2}$ peaks of cobalt oxide at $2+\left(\mathrm{CoO}, \mathrm{CoWO}_{4}\right)$ and $/$ or $3+\left(\mathrm{Co}_{3} \mathrm{O}_{4}\right)$ oxidation states (Ref 42). $\mathrm{CoO}$ and $\mathrm{CoWO}_{4}\left(\mathrm{Co}^{2+}\right)$ normally present clear satellite peaks at BE 786.3 and $802.6 \mathrm{eV}$, while $\mathrm{Co}_{3} \mathrm{O}_{4}$ does not because it contains both $\mathrm{Co}^{2+}$ and $\mathrm{Co}^{3+}$. It is seen that in all the 
Coating e4 $\left(30^{\circ}, 240 \mathrm{~mm}\right)$ Brittle tribofilm

Top view
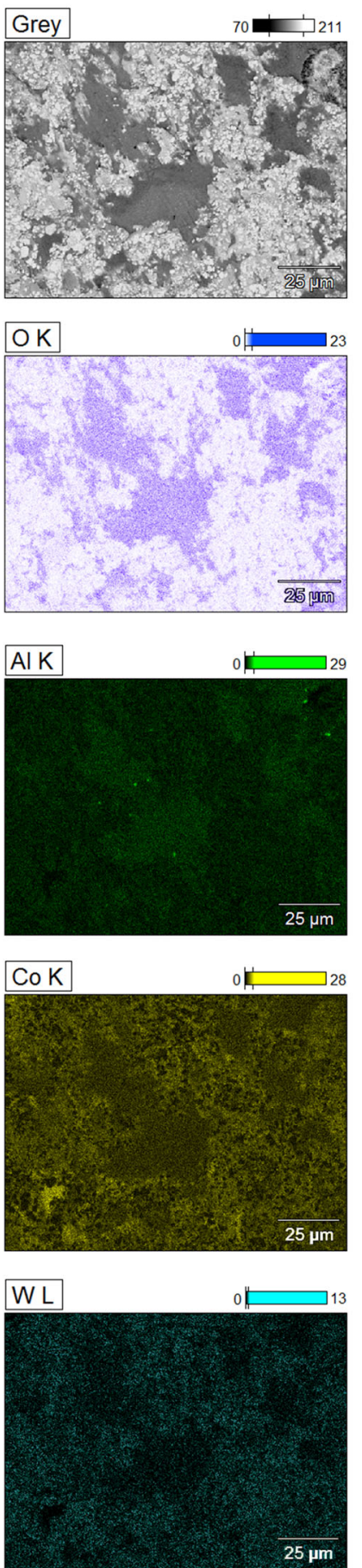
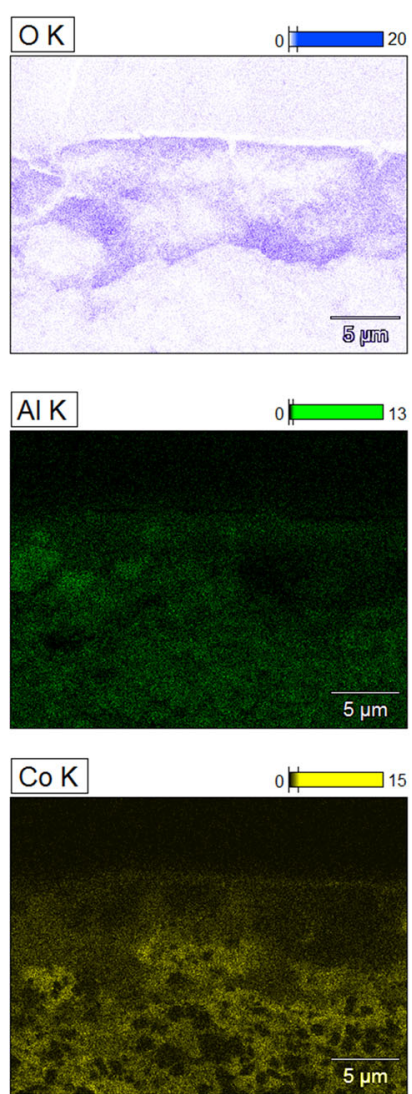

Cross section

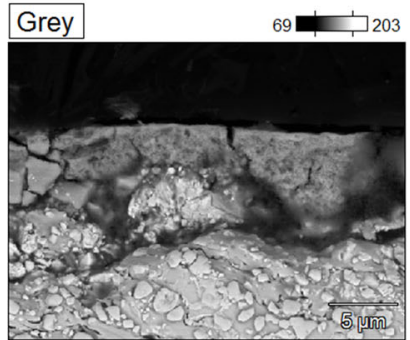

3 มูกิ
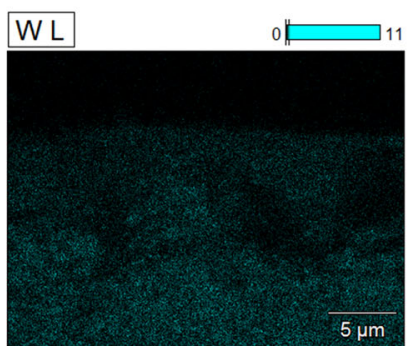

Coating a1 $\left(90^{\circ}, 120 \mathrm{~mm}\right)$ Tough tribofilm

Top view

Cross section
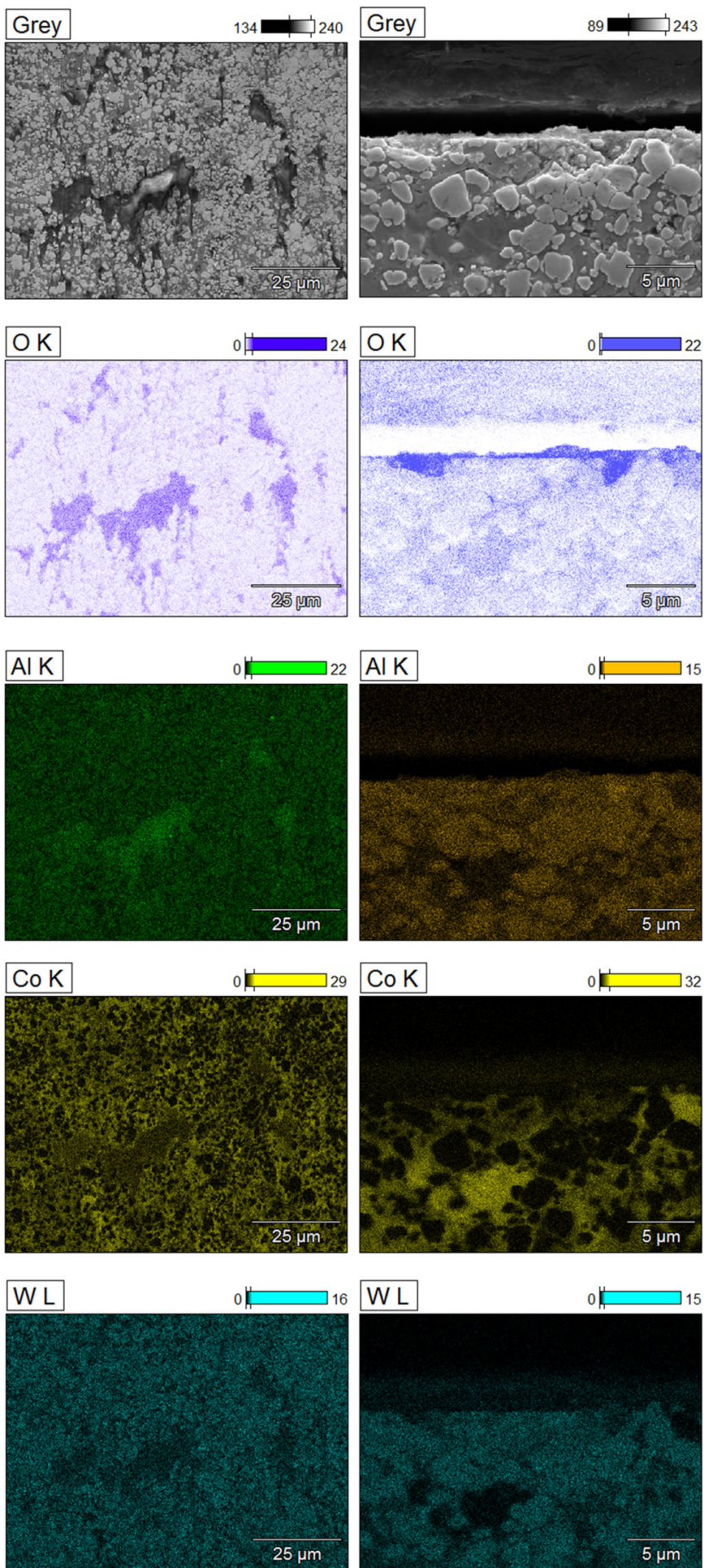

Fig. 10 EDS maps of surface (left column) and cross section (right column) of the tribofilm on coating e4 $\left(30^{\circ}, 240 \mathrm{~mm}\right)$

examined wear tracks, the satellite peaks in the Co2p spectra (786.3 and $802.6 \mathrm{eV}$ ) are clearly seen suggesting a dominance of the $\mathrm{Co}^{2+}$ versus $\mathrm{Co}^{3+}$. Thus, in accordance with the relevant literature, the presence of $\mathrm{WO}_{3}$ and/or $\mathrm{CoWO}_{4}$ can be confirmed in all the coatings.
It is worth noting that the relative intensity between the $\mathrm{W}_{4} \mathrm{f}_{7 / 2}$ and $\mathrm{W}_{4} \mathrm{f}_{5 / 2}$ peaks associated with $\mathrm{WO}_{3} / \mathrm{CoWO}_{4}$ and the respective peaks associated with WC from coating a1 (Fig. 11a) are substantially different from coatings a4 and e4 (Fig. 11b and c) favoring considerably WC against 

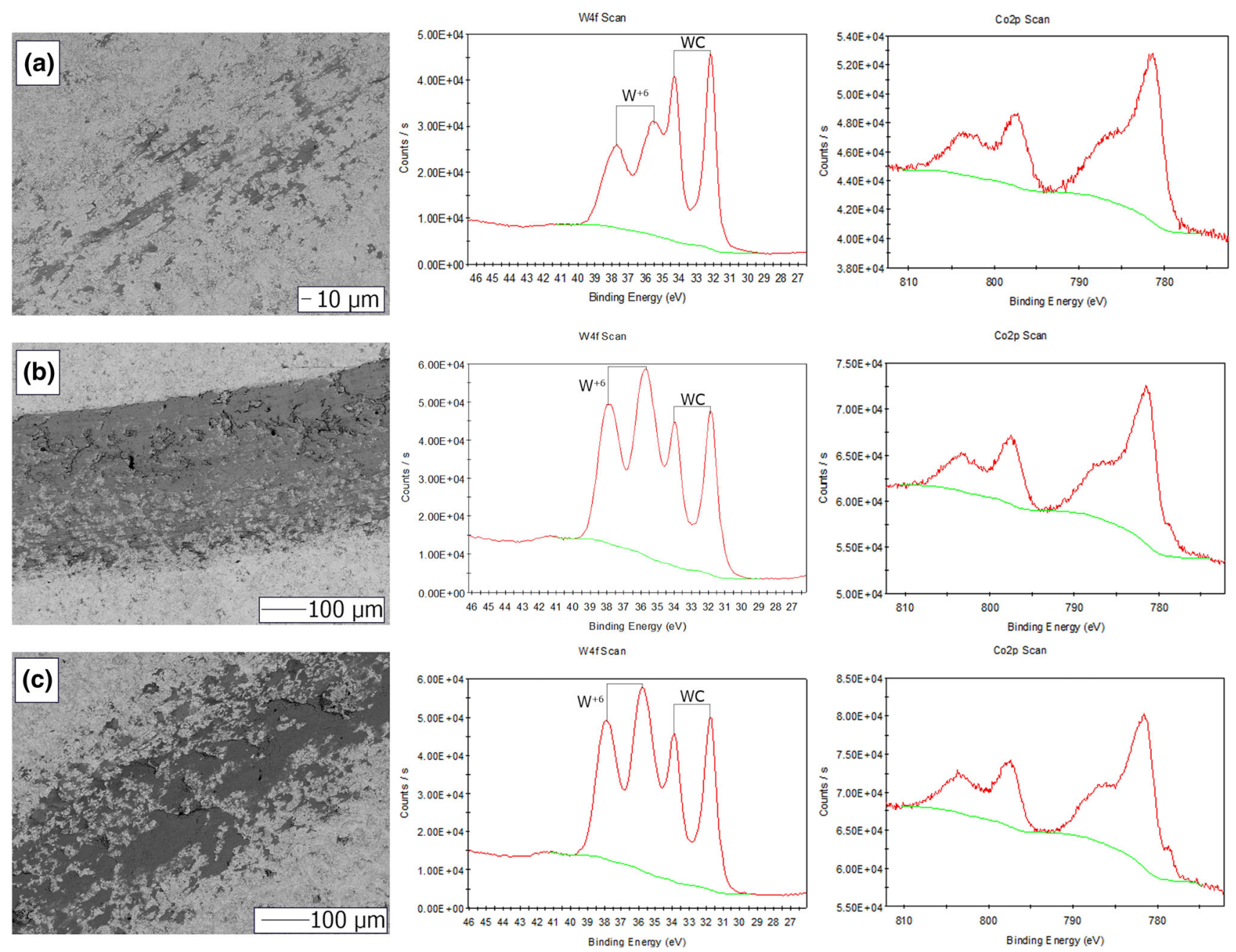

Fig. 11 BSC top views of wear tracks and corresponding W4f and Co2p spectra for the coatings (a) a1 (90, $120 \mathrm{~mm}),($ b) a4 (90, $240 \mathrm{~mm})$ and (c) e4 $\left(30^{\circ}, 240 \mathrm{~mm}\right)$

$\mathrm{WO}_{3} / \mathrm{CoWO}_{4}$. This observation is consistent with the relative tribofilm coverage and is attributed to the increased signal from the exposed WC that is detected in the case of coating a1. Conversely, the greater coverage of tribofilm on the wear tracks of coatings a 4 and e 4 conceals most of WC grains from the soft x-rays of the XPS measurement. In turn, this results in a higher detection rate of $\mathrm{WO}_{3} / \mathrm{CoWO}_{4}$ versus WC, which is reflected to the higher peak intensity of the $\mathrm{W}_{4} \mathrm{f}_{7 / 2}$ and $\mathrm{W}_{4} \mathrm{f}_{5 / 2}$ peaks associated with $\mathrm{WO}_{3}$ l $\mathrm{CoWO}_{4}$ in Fig. 11(b) and (c).

\section{Mechanisms of Wear}

Overall, the expected wear mechanisms for dry sliding on hardmetals were observed, yet they occurred at different intensities, yielding widely different degrees of wear damage, depending on the spray angle and spray distance that was employed for each coating. Two distinct pathways are proposed for the production of wear debris under the examined conditions:

(a) Plastic flow of binder relaxes the compressive residual stresses and leads to extrusion and loss of binder on the sliding interface (Ref 39) (Fig. 4a and b). This facilitates the fracturing, pull-out and WC grain loss from WC-clusters (as described above) that are exposed on the sliding interface. The removal of superficial WC grains leaves a micronscale cavities in their place (Fig. $4 \mathrm{c}$ and d), in addition to any existing surface imperfection caused by the grinding and polishing of the coating. The lost WC and binder will either be removed from the system, or will get trapped between the sliding bodies and initiate three-body abrasion wear that will be most aggressive locally to the pull-out origin, since at that stage the loose WC will be at its largest size (Ref 35). In that regard, the neighboring area to 
the WC pull-out is most prone to further WC loss. Thus, adjacent WC pull-outs occur which create pits that plausibly merge together during the course of the sliding test via further 3-body abrasion, as shown in Fig. 6(c) and (d). Meanwhile, the abrasive WC accelerates further binder extrusion, and in turn, more WC pull-outs occur, giving rise to a positive feedback loop and augmenting the whole process described above.

(b) Alternatively, in weaker coatings, subsurface cracks will initiate a few $\mu \mathrm{m}$ below the sliding surface (Fig. 9e), where the maximum shear stresses are developed (Ref 29, 43), and propagate via the splat boundaries, porosity, brittle/saturated Co-rich binder or $\mathrm{W}_{2} \mathrm{C}$, which would be the preferential paths for crack propagation (Ref 30, 44, 45), until they reach the surface or meet neighboring cracks. At this point, spallation will occur accompanied with a large-scale loss of coating volume. Expectedly, the debris generation via this mechanism happens at a significantly faster rate than the single WC pull-out mechanism. As a result, the probability of the generated debris getting trapped along the sliding and contributing to a positive feedback loop for further wear via 3-body abrasion as described above is higher. Furthermore, the higher wear rate will result in wider wear tracks and correspondingly larger contact area with the counter-body. In turn, the total volume of wear debris that is captured per sliding distance is higher, which accelerates the tribofilm build-up via the mechanism described above in a supplementary manner.

The degree of occurrence of each one of these two pathways described above ultimately depends on the coating's ability to sustain the subsurface shear stresses without initiating and propagating any cracks. Clearly, the decarburization, inter-splat cohesion, WC retention, compressive residual stress, uniform microstructure and porosity are critical factors in that respect and that is why the normal (to the target surface) component of velocity, particle plasticity and thermal history at impact (Ref 8, 9) are critical factors in determining the wear resistance of the coating.

Very long spray distances are detrimental for the wear performance of the coatings in a multitude of distinct ways. First, excessive heating of the particles in-flight results in $\mathrm{CO}$ and $\mathrm{CO}_{2}$ porosity in the coating microstructure. Such gaseous porosity has been seen in the coatings in this work (sprayed at $240 \mathrm{~mm}$ ) (Ref 9) and discussed in the literature (Ref 30). Secondly, long distances result in higher particle impact temperatures (Table 1), which, in turn, render the impinging particles susceptible to lose WC grains via a WC-embossing mechanism which is discussed in Ref 46.
That in addition to the complete thermal dissolution of smallest WC (high surface-to-volume ratio) in the coating due to excessive heating result in a significant depletion of WC support from the microstructure. Thirdly, extended flight times and overheating of the particles yield increased $\mathrm{W}_{2} \mathrm{C}$ and $\mathrm{Co}-\mathrm{W}-\mathrm{C}$ amorphous phases (Ref 9) in the binder, which are directly associated with its embrittlement. Lastly, at long spray distances, the peening stresses are significantly reduced during impact due to the lower particle velocities and higher temperature of particles (Table 1) which facilitates deformation at impact. This typically yields significantly less compressive residual stresses in the coating, which would provide crack suppression (Ref 8). In these ways, increased spray distance ultimately compromises the strength and toughness of the coating and promotes the second pathway of wear (b) involving subsurface failure, as described above.

When an optimal spray distance is maintained and the problems described above are avoided, the effect of oblique spray angle is also negative to the coating's wear performance but in a different manner than spray distance. Considering the carbide distribution in the starting powder, it is seen that significant portion of the WC grains lies in clustered WC-aggregates (Fig. 1), which are held together by the binder. In Ref 9, it was demonstrated that such clusters, along with large WC grains, were most susceptible to disengage from the powder particle and rebound at very oblique spray angles. Additionally, oblique spray angles at short spray distances lead to weaker inter-splat bonding and reduced compressive stresses due to the velocity vector losses during impact (Ref 8) but do not affect the extent of thermal decomposition of the powder particles since spray angle is irrelevant with the time of flight of the particles, avoiding the associated embrittlement of the binder. On that basis, subsurface failure due to shear stresses during sliding wear is suppressed, in comparison with the coatings sprayed at longer distances. As of that, the milder first pathway (a) of wear is more prominent, even at extreme oblique angles, when the spray distance is not too long. That explains the less deteriorating role of spray angle to wear performance, in comparison with spray distance (Fig. 2).

In terms of the interplay between spray angle and spray distance, in Ref 8 and 9 it is demonstrated that as the spray distance is increased, the phenomena that are associated with particle velocity vector losses due to oblique impact (preferential WC rebounding and peening stress transfer) are less prominent due to the increased plasticity of the hotter impinging particles. Nevertheless, spray angle never ceases to control the biased deposition of softer versus harder particles (or fractions of particles). This means that even at long spray distances, coatings sprayed at oblique angles will have a higher fraction of brittle amorphous 
binder (that originates from rapid crystallization from liquid state) than coating sprayed at the same distance but at normal spray angle (Ref 9). In such a way, the isolated effect of spray angle and spray distance stack-up and both contribute to the degradation of the coating's wear performance.

The factor that dictates whether a coating will develop a tribofilm that covers most of its sliding interface or not is the ratio of rate of wear debris getting captured along the sliding motion to the rate of wear debris removal from the system. Undoubtedly, the rate of wear debris captured in the sliding motion is directly related to the rate of wear debris production in general. The onset of a continuous tribofilm zone on coatings e1 and d2 (Fig. 3) occurs in a sector that runs along the trajectory of the wear track. This behavior suggests that a continuous tribofilm layer starts forming when a certain critical density of spallations and WC pull-outs occurs along one trajectory of the sliding motion. When this critical density is achieved, the rate of wear debris production becomes higher than the rate of wear debris removal from the system and in that manner increasingly more wear debris gets trapped between the sliding interfaces resulting in the build-up of a tribofilm layer. The sliding process on weak coatings that produce high volumes of debris leads to a fast formation of a thick layer of tribofilm, which under prolonged smearing is embrittled and leads to large cracks and spallations (Ref 47).

\section{Effect of Tribofilm on Friction Coefficient}

In Fig. 12, it is seen that COF rises to a maximum value in the first $170-200 \mathrm{~m}$. In most cases, this initial peak lies between 0.5 and 0.6. The initial rise of the COF in the dry sliding of cermet coatings has been widely observed in the literature, and it is attributed to the initial running-in stage of contact where the limited real contact area between the sliding interfaces is intensely deformed and worn away, until it is increased and equilibrium is achieved (Ref $35,40,43,48)$. In this running-in phase, significant cracking and material removal occurs, which is recorded as high COF (Ref 48). Even though the coatings were mirrorpolished prior testing, initial micro-protrusions and asperities of the coating or the alumina counter-body would have caused a running-in period where COF is relatively elevated, compared with the steady wear regime that follows. After that point, two distinct behaviors are observed: (1) either COF declines and stabilizes in the range $0.3-0.45$, or (2) $\mathrm{COF}$ is maintained at the $0.5-0.6$ region throughout the dry sliding test. In the former case, where COF is gradually reduced and stabilized at lower levels, steady state wear is achieved with notably less cracking and material removal in comparison with the running-in stage. Conversely, the prolonged elevated COF levels that some coatings present throughout the wear test indicate that the same degree of deformation and cracking occurs throughout the wear test as the initial running-in stage.

Looking back at Fig. 3, it is revealed the coatings that present continuous elevated COF are the same ones identified earlier with markedly higher levels (over 74\%) of tribofilm coverage on the wear track area (e2, e3, a4, b4, $\mathrm{c} 4, \mathrm{~d} 4, \mathrm{e} 4)$. Thus, there is an undisputable relation between the amount of tribofilm present of the wear tracks and the level and progression of the friction coefficient at low loads, such as the $10 \mathrm{~N}$ studied in this work. Considering the coatings that present high coverage of tribofilm layers, the repetitive deformation and tribo-oxidation of the tribofilm layer leads to its embrittlement as discussed above. In turn, dry sliding on brittle tribofilms gives rise to a perpetual cycle of tribofilm fracture (Fig. 7f), removal and regeneration that is reflected on the continuously elevated levels of the respective COF graphs in Fig. 12. Yet, this is in contradiction with a number of authors, e.g., Ref 34-36 where it is supported that tribofilm contributes in lowering the COF.

Across the relevant literature, the lubricating property of tribo-generated oxides is attributed (1) to the easy interplanar shearing found in the Magnéli phase of $\mathrm{WO}_{3}$ (Ref 49) or (2) to the significant difference in ionic potential of the sliding oxide pairs, that also results in low shear strength (Ref 50, 51) (relevant for $\mathrm{WO}_{3}$ interaction with $\mathrm{Al}_{2} \mathrm{O}_{3}$ and $\mathrm{CoWO}_{4}$ ). In the former case (Magnéli phase of $\mathrm{WO}_{3}$ ), the crystal lattice is distorted by the presence of oxygen, which results in greater interplanar distances and the associated weak cohesion (Ref 49) that facilitates interplanar shearing. In the latter case (sliding oxide species with high ionic potential difference), the lubricating properties originate from (1) low melting point of the compounds in the sliding interface that leads to easy shearing in elevated temperatures and (2) lower adhesive forces between the sliding oxide pair (Ref 50, 51).

However, as Wesmann et al. (Ref 37) showed, the presence of oxides with lubricating properties in the tribofilm does not necessarily yield a lubricous property of the tribofilm as whole. The tribofilm results from a repetitive process of uneven oxidation, mixing, sintering and heating/cooling cycles of the wear debris. From such a dynamic and random process, an epitaxial tribo-oxide formation with a uniform crystal structure is not possible. Instead, the tribofilm is found to be in a nano-crystallized phase (Fig. 9d), also seen in Ref 31 and 37. This microstructure hinders any material property that is sensitive to the crystal orientation such as the lubricating properties of the Magnéli phase (Ref 52). Furthermore, mixing tungsten oxide species with cobalt oxides is expected to result in higher friction of the sliding system 

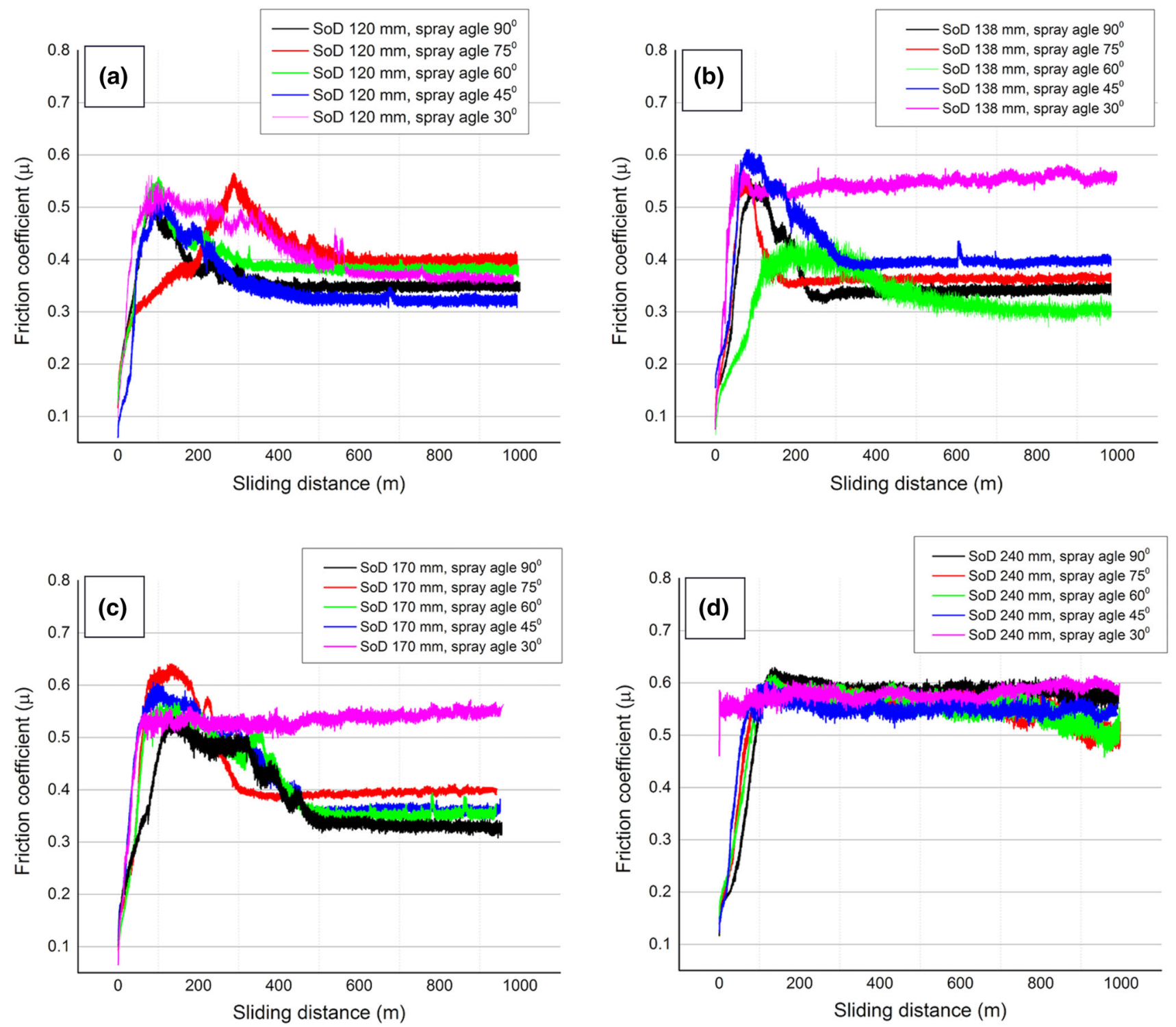

Fig. 12 Coefficient of friction vs. sliding distance graphs (a) coatings sprayed at $120 \mathrm{~mm}$, (b) coatings sprayed at $138 \mathrm{~mm}$, (c) coatings sprayed at $170 \mathrm{~mm}$, (d) coatings sprayed at $240 \mathrm{~mm}$

(Ref 51) although $\mathrm{CoO}$ is not expected to be formed in significant quantities in the wear track (Ref 37). Nonetheless, the inherently defective nano-crystallized structure, as a result of imperfect sintering and smearing at the tribofilm formation, induces crack propagation rather than shearing of lattice planes, in response to the sliding stresses.

Lastly, the $\mathrm{WO}_{3}$ that is grown in controlled oxidation conditions presents a porous structure (Ref 42). Considering the complex conditions under which oxides are produced during sliding, it is unlikely that any $\mathrm{WO}_{3}$ in the tribofilm will present a similar, porous microstructure, as $\mathrm{WO}_{3}$ which is produced in controlled oxidation environments. However, numerous authors (Ref 30, 31, 33) suggest the superiority of $\mathrm{CoWO}_{4}$ to $\mathrm{WO}_{3}$ in terms of antifriction properties, for that very reason, i.e., the denser structure of $\mathrm{CoWO}_{4}$ compared to the porous $\mathrm{WO}_{3}$. The analysis herein did not show evidence of any free-standing, porous $\mathrm{WO}_{3}$ in the tribofilm. Thus, the brittle behavior of the tribofilm is attributed exclusively in its microstructure as a composite, nano-crystallized film as discussed above.

In order to evaluate in detail the correlation between the tribofilm, wear performance and COF, image analysis was employed to quantify the apparent tribofilm coverage on the wear tracks after the dry sliding tests. Figure 13 illustrates the correlation of tribofilm area fraction versus the wear resistance and COF of the coatings. In Fig. 13, wear resistance follows an exponential decay rule. Meanwhile, COF presents a linear positive correlation with increasing tribofilm coverage fraction. Both correlations exhibit good fit to the measurements. Yet, the distribution of the data is 
noteworthy. Reflecting the observations about tribofilm coverage made earlier, there are two discrete groups of measurements with the first one being in a mild tribofilm coverage regime (black data points) and the second one in a severe one (red data points in Fig. 13). In more detail, tribofilm measurements span from $18 \%$ (a1) to $43 \%$ (a3), then there is a gap between 43 and $74 \%$ (e2) and the rest of the measurements lie in the range of $74 \%$ (e2) to $87 \%$ (a4).

From Fig. 12, it is evident that the evolution of COF during the sliding test is a direct and clear indicator of the formation or not of a brittle tribofilm layer. Furthermore, Fig. 12 suggests that the extent of tribofilm coverage on the wear track is a valid indicator of the severity of wear damage (at low loads), and as such it can be useful for rough estimates via macroscopic examination of the wear tracks.

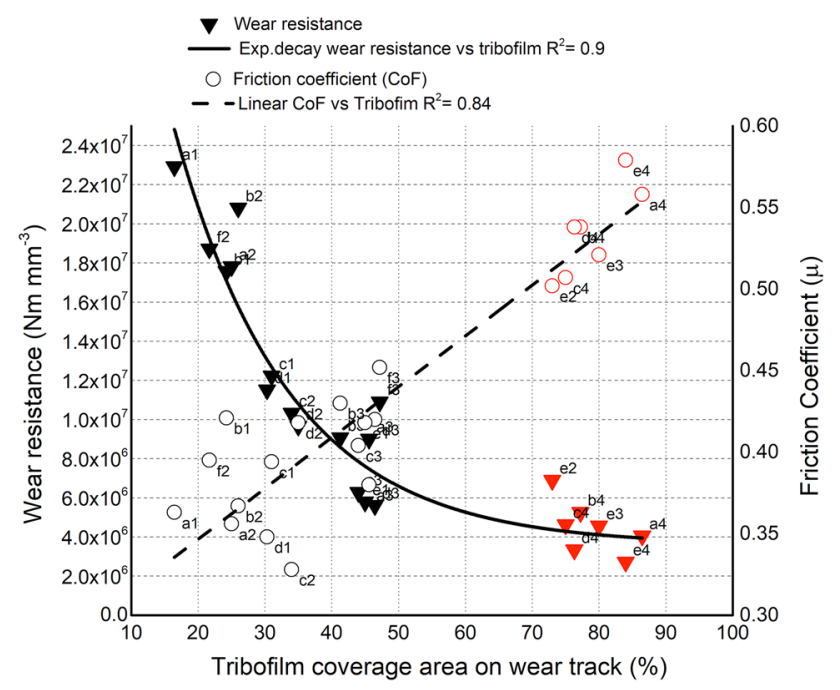

Fig. 13 Wear resistance and COF vs. tribofilm coverage area $\%$ of the wear track

\section{The Beneficial Role of Steep Spray Angles at Long Spray Distances}

The wear behavior of coatings sprayed at the distance of $240 \mathrm{~mm}$ is distinct from the shorter spray distances examined because it presents a significant reduction in SWR when the spray angle is $75^{\circ}$, in comparison with $90^{\circ}$ (Table 2, Fig. 2). This improvement is accompanied by a notable reduction in the number of large craters and tribofilm coverage (Fig. 3). In Ref 9, it was shown that coating a4 $\left(90^{\circ}, 240 \mathrm{~mm}\right)$ had extensive non-uniformity in the distribution of WC grains in its microstructure. Large Co-rich lakes, depleted of any WC reinforcement, were identified to exist among the WC grains. Such Co-rich lakes can be seen in Fig. 14(a), where they appear as completely dark areas, due to the high level of contrast that was used in the backscatter images.

At $75^{\circ}$ of deposition angle and same spray distance (coating b4), there was a remarkable improvement in the distribution of WC grains in the microstructure (Fig. 14b) that also was reflected in the lower binder mean free path (Ref 9) and higher microhardness (Ref 8) of that coating. In view of the earlier discussion, the Co-rich lakes of coating a4 $\left(90^{\circ}, 240 \mathrm{~mm}\right)$ would have been very easily plowed and extruded in dry sliding conditions, along with inadequately supported WC. Thus, it is presumed that such material removal occurred very early in the wear tests, initiating 3 -body abrasion earlier than in coating b4 $\left(75^{\circ}, 240 \mathrm{~mm}\right)$, which resulted in the observed reduced SWR of coating b4. The more uniform distribution of WC grains in coating b4 is attributed to the increased aspect ratio of splats associated with oblique spray angles. Previous work (Ref 14, 15) demonstrates the improvement in phase distribution which results from oblique deposition angles, and in Ref 36, 53 the beneficial role of a good distribution of WC in the microstructure to the sliding wear resistance is demonstrated. Furthermore, previous work on WC-Co deposition via atmospheric plasma spray (Ref 5,11) and HVOF (Ref 10) showed a spike on deposition rate occurring at $75^{\circ}$ spray angle suggesting that the better distribution of $\mathrm{WC}$
Fig. 14 BSC SEM images of coatings (a) a4 $\left(90^{\circ}, 240 \mathrm{~mm}\right)$ and (b) b4 $\left(75^{\circ}, 240 \mathrm{~mm}\right)$ adopted from Ref 9
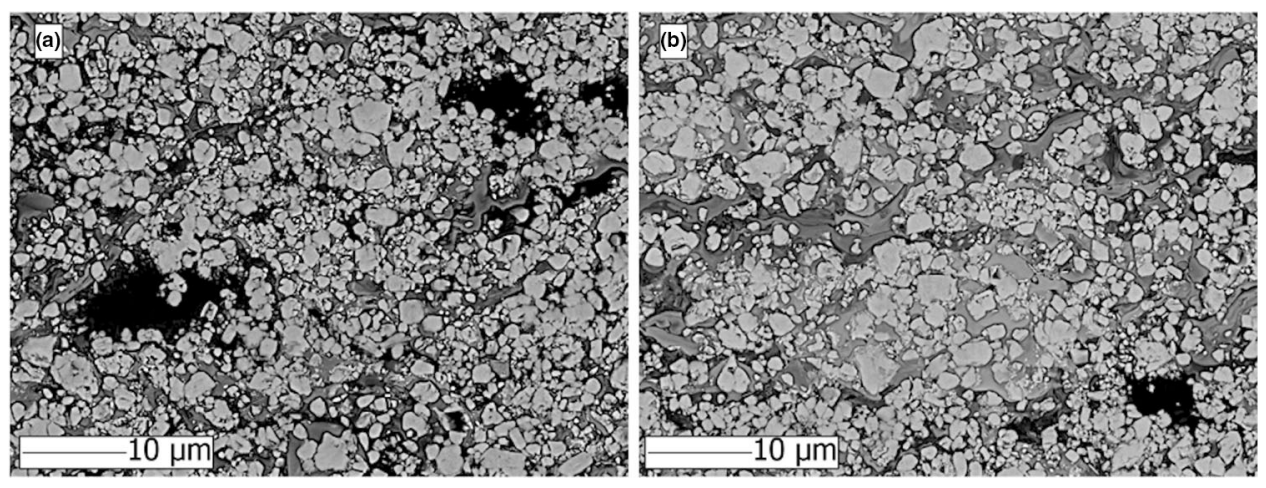
and better deposition rate might be related under a common mechanism occurring at these conditions (small inclination from the normal deposition angle and adequately high deposition temperature).

\section{Conclusions}

Twenty WC-17Co coatings were subjected to low load dry sliding wear tests and the resulting wear resistance and COF were critically discussed and correlated to (1) the varying spray kinematic conditions and (2) other microstructural and mechanical properties of the coatings. Wear resistance is found to be negatively correlated both with oblique deposition angles and increased stand-off distance but in different manner with each one. Longer spray distances result in (1) depletion of smallest WC due to complete thermal dissolution, (2) nano-crystallized brittle binder and (3) reduced compressive residual stress due to the lower particle velocity and lower peening, associated with higher particle temperatures at impact. In that way, such coatings fail predominantly via subsurface crack generation and propagation that ultimately leads to large-scale material loss and early formation of a tribofilm layer that is, itself, embrittled with the repetitive deformation, tribo-oxidation and build-up to a critical volume that renders it susceptible to subsurface shear cracking during the sliding wear. Conversely, oblique spray angles are responsible for the preferential deposition of softer (hotter) phases versus harder (colder) at the instance of impact due to easier plastic deformation and the discriminating role of the spray angle-associated velocity component losses. This occurs regardless of the spray distance. At short spray distances, where the impinging particles are mostly solid this phenomenon yields (1) depletion of the largest WC via preferential rebounding at impact and (2) reduced inter-splat cohesion and compressive residual stresses. Yet, the toughness of the binder is not as compromised as coatings sprayed at longer distances due to minimum thermal decomposition during the short flight. This limits, relatively, the coating failure via subsurface cracking, and by doing so, it delays the onset of large-scale debris production that would lead to 3-body abrasion and tribofilm generation. In that manner, extended decarburization of particles due to long spray distance is proved to be more catastrophic than oblique spray angles, in regard to the wear resistance of the coatings. Regarding the interplay of spray distance and spray angle, the negative influence of spray angle and spray distance stack-up with one another since longer spray distances will result in increased heating of the particles and oblique spray angles will lead to a larger relative fraction of the coatings originating from the overheated (and decarburized) particles (or fractions of particles).

At long spray distances, steep oblique spray angles $\left(75^{\circ}\right)$ have a beneficial effect on the wear resistance of coatings due to the better distribution of WC in the microstructure and insignificant normal velocity vector losses that occur at such small deviations from $90^{\circ}$ spray angle. This is enabled by the increased plasticity of the impinging particles that is associated with long spray distances.

Regarding the tribofilm, its formation is dictated by the relative rates of wear debris production and removal from the system. Once a critical rate of wear debris production is achieved, more debris is trapped in the sliding interfaces than removed from the system and a tribofilm layer is progressively built up. Furthermore, tribofilm coverage on the wear track appears to be positively correlated with $\mathrm{COF}$ and negatively correlated with wear resistance. The tribofilm does not appear to provide any lubrication in the sliding process. On the contrary, prolonged sliding under the low load led to its embrittlement which maintains the $\mathrm{COF}$ at high levels due to its continuous cracking and regeneration.

Acknowledgments The authors would like to acknowledge the technical support of prof. Angeliki Lekatou and Anthi Poulia at University of Ioannina GR for conducting the wear tests. We would like also to acknowledge Dr. David Jones and Amr Mahmoud Soliman (University of Surrey UK) for their assistance in the characterization of the samples.

Funding This work was supported by the UK Engineering and Physical Sciences Research Council (EPSRC) Project Grant: EP/ K027530/1. The funding source had no influence in the collection, analysis and interpretation of data.

Conflict of Interest The authors declare that they have no conflict of interest.

Open Access This article is distributed under the terms of the Creative Commons Attribution 4.0 International License (http://crea tivecommons.org/licenses/by/4.0/), which permits unrestricted use, distribution, and reproduction in any medium, provided you give appropriate credit to the original author(s) and the source, provide a link to the Creative Commons license, and indicate if changes were made.

\section{References}

1. C. Verdon, A. Karimi, and J.- Martin, A Study of High Velocity Oxy-Fuel Thermally Sprayed Tungsten Carbide-Based Coatings. Part 1: Microstructures, Mater. Sci. Eng. A, 1998, 246, p 11-24

2. L. Berger, Application of Hardmetals as Thermal Spray Coatings, Int. J. Refract. Met. Hard Mater., 2015, 49, p 350-364

3. J.A. Picas, M. Punset, M. Teresa Baile, E. Martín, and A. Forn, Tribological Evaluation of HVOF Thermal-Spray Coatings as a Hard Chrome Replacement, Surf. Interface Anal., 2011, 43, p 1346-1353 
4. A. Ibrahim and C.C. Berndt, Fatigue and Deformation of HVOF Sprayed WC-Co Coatings and Hard Chrome Plating, Mater. Sci. Eng. A, 2007, 456, p 114-119

5. W. Tillmann and B. Krebs, Influence of Handling Parameters on Coating Characteristics in Order to Produce Near-Net-Shape Wear Resistant Coatings, J. Therm. Spray Technol., 2012, 21, p 644-650

6. C. Lyphout and S. Björklund, Internal Diameter HVAF Spraying for Wear and Corrosion Applications, J. Therm. Spray Technol., 2014, 24, p 235-243

7. I.F. Secosan, D. Utu, V.A. Serban, and W. Brandl, Wear Resistance of Internal WC-CoCr Coatings Produced by High Velocity Oxy-Fuel Spraying, Diffus. Defect Data Pt. B, 2012, 188, p 416421

8. V. Katranidis, S. Gu, B. Allcock, and S. Kamnis, Experimental Study of High Velocity Oxy-Fuel Sprayed WC-17Co Coatings Applied on Complex Geometries. Part A: Influence of Kinematic Spray Parameters on Thickness, Porosity, Residual Stresses and Microhardness, Surf. Coat. Technol., 2017, 311, p 206-215

9. V. Katranidis, S. Gu, T.R. Reina, E. Alpay, B. Allcock, and S. Kamnis, Experimental Study of High Velocity Oxy-Fuel Sprayed WC-17Co Coatings Applied on Complex Geometries. Part B: Influence of Kinematic Spray Parameters on Microstructure, Phase Composition and Decarburization of the Coatings, Surf. Coat. Technol., 2017, 328, p 499-512

10. W. Tillmann, I. Baumann, P. Hollingsworth, and I. Laemmerhirt, Influence of the Spray Angle on the Properties of HVOF Sprayed WC-Co Coatings Using $(-10+2 \mu \mathrm{m})$ Fine Powders, J. Therm. Spray Technol., 2013, 22, p 272-279

11. W. Tillmann, E. Vogli, and B. Krebs, Influence of the Spray Angle on the Characteristics of Atmospheric Plasma Sprayed Hard Material Based Coatings, J. Therm. Spray Technol., 2008, 17, p 948-955

12. F. Trifa, G. Montavon, and C. Coddet, On the Relationships Between the Geometric Processing Parameters of APS and the $\mathrm{Al}_{2} \mathrm{O}_{3}-\mathrm{TiO}_{2}$ Deposit Shapes, Surf. Coat. Technol., 2005, 195, p 54-69

13. M. Gui, R. Eybel, B. Asselin, S. Radhakrishnan, and J. Cerps, Influence of Processing Parameters on Residual Stress of High Velocity Oxy-Fuel Thermally Sprayed WC-Co-Cr Coating, $J$. Mater. Eng. Perform., 2012, 21, p 2090-2098

14. G. Montavon, S. Sampath, C.C. Berndt, H. Herman, and C. Coddet, Effects of the Spray Angle on Splat Morphology During Thermal Spraying, Surf. Coat. Technol., 1997, 91, p 107-115

15. E. Strock, P. Ruggiero, and D. Reynolds, The Effect of Off-Angle Spraying on the Structure and Properties of $\mathrm{HVOF} \mathrm{WC} / \mathrm{CoCr}$ Coatings, in Proceedings of International Thermal Spray Conference (2001), pp. 671-676

16. Š. Houdková, M. Kašparová, and F. Zahálka, The Influence of Spraying Angle on Properties of HVOF Sprayed Hardmetal Coatings, J. Therm. Spray Technol., 2010, 19, p 893-901

17. A. Candel and R. Gadow, Optimized Multiaxis Robot Kinematic for HVOF Spray Coatings on Complex Shaped Substrates, Surf. Coat. Technol., 2006, 201, p 2065-2071

18. Technical Bulletin AMPERIT 526 WC-Co 83/17 agglomerated sintered (2011)

19. B. Allock, S. Gu, and S. Kamnis, Nozzle for a Thermal Spray Gun and Method of Thermal Spraying, EP20100711455 (2012)

20. A. Lekatou, D. Sioulas, A.E. Karantzalis, and D. Grimanelis, A Comparative Study on the Microstructure and Surface Property Evaluation of Coatings Produced from Nanostructured and Conventional WC-Co Powders HVOF-Sprayed on Al7075, Surf. Coat. Technol., 2015, 276, p 539-556

21. C. Lyphout and K. Sato, Screening Design of Hard Metal Feedstock Powders for Supersonic Air Fuel Processing, Surf. Coat. Technol., 2014, 258, p 447-457
22. C. Lyphout, K. Sato, S. Houdkova, E. Smazalova, L. Lusvarghi, G. Bolelli, and P. Sassatelli, Tribological Properties of Hard Metal Coatings Sprayed by High-Velocity Air Fuel Process, J. Therm. Spray Technol., 2016, 25, p 331-345

23. L. Berger, S. Saaro, T. Naumann, M. Wiener, V. Weihnacht, S. Thiele, and J. Suchánek, Microstructure and Properties of HVOFSprayed Chromium Alloyed WC-Co and WC-Ni Coatings, Surf. Coat. Technol., 2008, 202, p 4417-4421

24. J. Yuan, C. Ma, S. Yang, Z. Yu, and H. Li, Improving the Wear Resistance of HVOF Sprayed WC-Co Coatings by Adding Submicron-Sized WC Particles at the Splats' Interfaces, Surf. Coat. Technol., 2016, 285, p 17-23

25. R.J.K. Wood, Tribology of Thermal Sprayed WC-Co Coatings, Int. J. Ref. Met. Hard Mater., 2010, 28, p 82-94

26. G. Bolelli, T. Börner, A. Milanti, L. Lusvarghi, J. Laurila, H. Koivuluoto, K. Niemi, and P. Vuoristo, Tribological Behavior of HVOF- and HVAF-Sprayed Composite Coatings Based on FeAlloy + WC-12\% Co, Surf. Coat. Technol., 2014, 248, p 104112

27. G. Bolelli, I. Hulka, H. Koivuluoto, L. Lusvarghi, A. Milanti, K. Niemi, and P. Vuoristo, Properties of WC-FeCrAl Coatings Manufactured by Different High Velocity Thermal Spray Processes, Surf. Coat. Technol., 2014, 247, p 74-89

28. G. Bolelli, L.- Berger, T. Börner, H. Koivuluoto, L. Lusvarghi, C. Lyphout, N. Markocsan, V. Matikainen, P. Nylén, P. Sassatelli, R. Trache, and P. Vuoristo, Tribology of HVOF- and HVAFsprayed WC-10Co4Cr Hardmetal Coatings: A Comparative Assessment, Surf. Coat. Technol., 2015, 265, p 125-144

29. M. Jafari, M.H. Enayati, M. Salehi, S.M. Nahvi, S.N. Hosseini, and C.G. Park, Influence of Nickel-Coated Nanostructured WCCo Powders on Microstructural and Tribological Properties of HVOF Coatings, J. Therm. Spray Technol., 2014, 23, p 14561469

30. Z. Geng, S. Hou, G. Shi, D. Duan, and S. Li, Tribological Behaviour at Various Temperatures of WC-Co Coatings Prepared Using Different Thermal Spraying Techniques, Tribol. Int., 2016, 104, p 36-44

31. Z. Geng, S. Li, D.L. Duan, and Y. Liu, Wear Behaviour of WCCo HVOF Coatings at Different Temperatures in Air and Argon, Wear, 2015, 330-331, p 348-353

32. H. Engqvist, H. Högberg, G.A. Botton, S. Ederyd, and N. Axén, Tribofilm Formation on Cemented Carbides in Dry Sliding Conformal Contact, Wear, 2000, 239, p 219-228

33. Q. Yang, T. Senda, and A. Hirose, Sliding Wear Behavior of WC$12 \%$ Co Coatings Elevated Temperatures, Surf. Coat. Technol., 2006, 200, p 4208-4212

34. D. Wang, B.- Zhang, C. Jia, F. Gao, Y.- Yu, X.- Zhao, and Z. Bai, Microstructure and Tribological Properties of Plasma-Sprayed WC-17 Co Coatings with Different Carbide Grain Size Distribution, Jpn. Soc. Powder Powder Metall., 2016, 63, p 688-696

35. Q. Yang, T. Senda, and A. Ohmori, Effect of Carbide Grain Size on Microstructure and Sliding Wear Behavior of HVOF-Sprayed WC-12\% Co Coatings, Wear, 2003, 254, p 23-34

36. J.M. Guilemany, J.M. Miguel, S. Vizcaino, and F. Climent, Role of Three-Body Abrasion Wear in the Sliding Wear Behaviour of WC-Co Coatings Obtained By Thermal Spraying, Surf. Coat. Technol., 2001, 140, p 141-146

37. J.A.R. Wesmann and N. Espallargas, Elucidating the Complex Role of Surface Oxides Formed During Sliding of Self-Mated Warm Sprayed WC-CoCr in Different Environments, Tribol. Int., 2016, 94, p 360-372

38. G.W. Stachowiak and A.W. Batchelor, Corrosive and Oxidative Wear: 13, Engineering Tribology, 3rd ed., G.W. Stachowiak and A.W. Batchelor, Ed., Butterworth-Heinemann, Burlington, 2006, p 573-593 
39. J. Larsen-Basse, Binder Extrusion in Sliding Wear of WC-Co Alloys, Wear, 1985, 105, p 247-256

40. S. Usmani, S. Sampath, D.L. Houck, and D. Lee, Effect of Carbide Grain Size on the Sliding and Abrasive Wear Behavior of Thermally Sprayed WC-Co Coatings, Tribol. Trans., 1997, 40, p 470-478

41. M.T. Postek and A.E. Vladar, Does Your SEM Really Tell the Truth? How Would You Know? Part 4: Charging and its Mitigation, Proc. SPIE, 2015, 35, p 355-361

42. L. Chen, D. Yi, B. Wang, H. Liu, and C. Wu, Mechanism of the Early Stages of Oxidation of WC-Co Cemented Carbides, Corros. Sci., 2016, 103, p 75-87

43. J. Yuan, Y. Zhu, X. Zheng, Q. Ruan, and H. Ji, Improvement in Tribological Properties of Atmospheric Plasma-Sprayed WC-Co Coating Followed by $\mathrm{Cu}$ Electrochemical Impregnation, Appl. Surf. Sci., 2009, 255, p 7959-7965

44. P. Chivavibul, M. Watanabe, S. Kuroda, and K. Shinoda, Effects of Carbide Size and Co Content on the Microstructure and Mechanical Properties of HVOF-sprayed WC-Co Coatings, Surf. Coat. Technol., 2007, 202, p 509-521

45. D.A. Stewart, P.H. Shipway, and D.G. McCartney, Abrasive Wear Behaviour of Conventional and Nanocomposite HVOFSprayed WC-Co Coatings, Wear, 1999, 225-229, p 789-798

46. C. Li, G. Ji, Y. Wang, and K. Sonoya, Dominant Effect of Carbide Rebounding on the Carbon Loss During High Velocity Oxy-
Fuel Spraying of $\mathrm{Cr}_{3} \mathrm{C}_{2}-\mathrm{NiCr}$, Thin Solid Films, 2002, 419, p 137143

47. N. Ma, L. Guo, Z. Cheng, H. Wu, F. Ye, and K. Zhang, Improvement on Mechanical Properties and Wear Resistance of HVOF Sprayed WC-12Co Coatings by Optimizing Feedstock Structure, Appl. Surf. Sci., 2014, 320, p 364-371

48. H. Wang, X. Wang, X. Song, X. Liu, and X. Liu, Sliding wear behavior of nanostructured WC-Co-Cr coatings, Appl. Surf. Sci., 2015, 355, p 453-460

49. T. Reeswinkel, D. Music, and J.M. Schneider, Coulomb-Potential-Dependent Decohesion of Magnieli Phases, 2010, J. Phys. Condens. Matter, 2010, 22, p 1-4

50. A. Erdemir, A Crystal Chemical Approach to the Formulation of Self-Lubricating Nanocomposite Coatings, Surf. Coat. Technol., 2005, 200, p 1792-1796

51. A. Erdemir, S. Li, and Y. Jin, Relation of Certain Quantum Chemical Parameters to Lubrication Behavior of Solid Oxides, Int. J. Mol. Sci., 2005, 6, p 203-218

52. O.D. Greenwood, S.C. Moulzolf, P.J. Blau, and R.J. Lad, The Influence of Microstructure on Tribological Properties of $\mathrm{WO}_{3}$ Thin Films, Wear, 1999, 232, p 84-90

53. S. Liu, D. Sun, Z. Fan, H. Yu, and H. Meng, The Influence of HVAF Powder Feedstock Characteristics on the Sliding Wear Behaviour of WC-NiCr Coatings, Surf. Coat. Technol., 2008, 202, p 4893-4900 